\title{
Indo-Pacific Sea Surface Temperature Perturbations Associated with Intraseasonal Oscillations of Tropical Convection
}

\author{
JeAn Philippe Duvel \\ Laboratoire de Météorologie Dynamique, ENS, Paris, France \\ JÉRÔME VIALARD \\ Institut de Recherche pour le Développement, Laboratoire d'Océanographie Dynamique et de Climatologie, Université Paris VI, \\ Paris, France
}

(Manuscript received 29 April 2005, in final form 17 January 2006)

\begin{abstract}
The intraseasonal variability (ISV; 20-90 days) of the SST is examined using $7 \mathrm{yr}$ of data from the Tropical Rainfall Measuring Mission's (TRMM) Microwave Imager (TMI). The ISV of the SST is larger in the summer hemisphere and in regions of relatively small ocean mixed layer depth (MLD). For these regions, the reddening of the SST spectrum in regard to the surface flux spectrum suggests that the ISV of the SST is mostly controlled by the integration of the local surface forcing by ocean mixed layer. However, the precise origin of large-scale organized perturbations of the SST also depends on region and season.

Since the ISV of the convection is an intermittent phenomenon, the local mode analysis (LMA) technique is used to detect only the ensemble of intraseasonal events that are well organized at large scale. The LMA technique is further developed in this paper in order to perform multivariate analysis given patterns of SST and surface wind perturbations associated specifically with these intraseasonal events. During boreal winter, the basin-scale eastward propagation of the convective perturbation is present only over the Indian Ocean Basin. The intraseasonal SST response to convective perturbations is large and recurrent over thin mixed layer regions located north of Australia and in the Indian Ocean between $5^{\circ}$ and $10^{\circ} \mathrm{S}$. By contrast, there is little SST response in the western Pacific basin and no clear eastward propagation of the convective perturbation. During boreal summer, the SST response is large over regions with thin mixed layers located north of the Bay of Bengal, in the Arabian Sea, and in the China Sea. The northeastward propagation of the convective perturbation over the Bay of Bengal is associated with a standing oscillation of the SST and the surface wind between the equator and the northern part of the bay. In fact, many intraseasonal events mostly concern a single basin, suggesting that the interbasin organization is not a necessary condition for the existence of coupled intraseasonal perturbations of the convection.

The perturbation of the surface wind tends to be larger to the west of the large-scale convective perturbation (like for a Gill-type dynamical response). For eastward propagating perturbations, the cooling due to the reinforcement of the wind (i.e., surface turbulent heat flux) thus generally lags the radiative cooling due to the reduction of the surface solar flux by the convective cloudiness. This large-scale Gill-type response of the surface wind also cools the surface to the west of the basin (northwest Arabian Sea and northwest Pacific Ocean), even if the convection is locally weak. An intriguing result is a frequently occurring small delay between the maximum surface wind and the minimum SST. Different explanations are invoked, like a rapid surface cooling due to the vanishing of an ocean warm layer (diurnal surface warming due to solar radiation in low wind conditions) as soon as the wind increases.
\end{abstract}

\section{Introduction}

The intraseasonal variability (ISV) of deep convection is one of the most organized and reproducible

Corresponding author address: Jean Philippe Duvel, Laboratoire de Météorologie Dynamique, ENS, 75231 Paris, CEDEX 05, France.

E-mail: jpduvel@1md.ens.fr

DOI: $10.1175 / J C L I 4144.1$

(C) 2007 American Meteorological Society large-scale perturbations in the Tropics, with maximum amplitude over the Indo-Pacific region. Over the Indian Ocean, this ISV has a strong seasonality. During the summer monsoon, the convective perturbation propagates northward from the equator to the Indian peninsula with maximum amplitude over the Bay of Bengal (see Lawrence and Webster 2002). These summer perturbations are strongly tied to the break and active phases of the Indian summer monsoon that 
modulate the seasonal mean rainfall (Webster et al. 1998; Goswami and Ajaya Mohan 2001). During winter, the maximum amplitude of the convective perturbation is located between the equator and $15^{\circ} \mathrm{S}$. This perturbation propagates eastward from the western Indian Ocean to the central Pacific. This winter variability is generally referenced as the Madden-Julian oscillation (MJO; see Madden and Julian 1994 for a review). These perturbations are associated with westerly wind bursts generating important surface flux perturbations (e.g., Weller and Anderson 1996; Duvel et al. 2004). Many studies suggest that these westerly wind bursts can also play an important role in the onset of El Niño events when they have significant amplitude along the equator in the western Pacific Ocean (e.g., McPhaden 1999; Lengaigne et al. 2002).

The mechanisms for the generation and the evolution of the intraseasonal variability of the deep convection over the Indo-Pacific region are not perfectly understood. In particular, recent modeling studies suggest that air-sea interactions could play an important role during both summer and winter (e.g., Waliser et al. 1999; Inness and Slingo 2003; Maloney and Sobel 2004). Observations have also revealed SST perturbations of up to $3 \mathrm{~K}$ in relation with the ISV of the convection in the China Sea (Kawamura 1988), in the Bay of Bengal (Sengupta and Ravichandran 2001), and in the western Pacific (e.g., Anderson et al. 1996). Recent satellite measurement of the SST by the Tropical Rainfall Measuring Mission's (TRMM) Microwave Imager (TMI) (Wentz et al. 2000) also revealed large SST perturbations during Northern Hemisphere $(\mathrm{NH})$ during the 1999 winter in the Indian Ocean (Harrison and Vecchi 2001; Duvel et al. 2004, hereafter DRV). These large SST variations, identified with the TMI satellite dataset, were confirmed by in situ data by DRV. Previous studies using the Reynolds and Smith (1994) weekly SST analyses gave far smaller SST variability related to the convective ISV (e.g., Jones et al. 1998; Shinoda et al. 1998; Woolnough et al. 2000). This is due in part to the screening effect of the cloudiness that prevents the estimation of the SST by satellite measurements in the infrared atmospheric window. This screening effect likely reduces the estimated ISV of the SST by masking the surface cooling during convective events.

During winter 1999, an intraseasonal SST perturbation of more than $1.5 \mathrm{~K}$ over a large region in the Indian Ocean between $5^{\circ}$ and $10^{\circ} \mathrm{S}$ was found in both in situ and TMI SST data. From this observation, Harrison and Vecchi (2001) concluded that the strong SST variations are mainly due to vertical and horizontal heat transport with the vertical exchange with the cold sub- surface being more efficient during the winter season during which the thermocline is closer to the surface. However, DRV concluded based on a forced oceanic GCM that, due to the shallow ocean mixed layer in this region, the atmospheric fluxes could be sufficient to explain the observed SST anomalies with the subsurface cooling remaining negligible. This interpretation is closer to the results found by Shinoda and Hendon (1998, 2001) over the western Pacific warm pool during the Tropical Ocean Global Atmosphere Coupled Ocean-Atmosphere Response Experiment (TOGA COARE) (see also Weller and Anderson 1996; Anderson et al. 1996). DRV also suggested that formation of a warm layer prior to the cooling event might contribute to the enhancement of the SST perturbation.

The balance between the different physical sources that can explain the strong intraseasonal SST perturbation is still unknown and is probably variable from one event to another. A strong point however is that the shallow thermocline between $5^{\circ}$ and $10^{\circ} \mathrm{S}$, due to average Ekman pumping during $\mathrm{NH}$ winter, is a fundamental feature in helping to explain these SST perturbations in the Indian Ocean. This shallow thermocline makes cold water readily available to cool the surface by vertical mixing or local upwelling; but, on the other hand, it also limits strongly the depth of the mixed layer, making it more responsive to surface forcing. This surface forcing perturbation itself is due to various physical processes that may have different phasing relative to the maximum convective activity. These physical processes are mainly the screening of the solar heat flux by the cloudiness, evaporative cooling, vertical mixing, and, potentially, Ekman pumping linked to wind bursts. DRV showed that the latitudinal position of the maximum SST variability was the result of agreement between the position of the region of maximum flux perturbation (spanning the equator) and the region where the thermocline is shallow (between $5^{\circ}$ and $12^{\circ} \mathrm{S}$ ). Results of the forced OGCM also showed that the salinity perturbation induced by strong rain under convection and the intraseasonal Ekman pumping perturbation could play some role in the large SST response by limiting the mixed layer deepening induced by the wind perturbation.

The present study aims at characterizing the SST perturbations associated with large-scale organized convective ISV events over the whole Indo-Pacific region. This study, covering the 1998-2004 period, is mainly based on the TMI measurements for the SST and on the National Oceanic and Atmospheric Administration's (NOAA) OLR dataset (Liebmann and Smith 1996) as a proxy for the tropical convective activity. In addition, in order to isolate intraseasonal convective 
events that are organized at large scales from the background red-noise variability at these time scales (say 20-90 days in a broad sense), we use the local mode analysis (LMA) approach (Goulet and Duvel 2000; Duvel et al. 2004). A multivariate LMA is developed here in order to extract SST and surface wind perturbations related specifically to large-scale organized convective perturbations. This approach will thus also filter out the ISV of the SST linked to oceanic internal variability such as tropical instability waves in the eastern equatorial Pacific and Atlantic Oceans (e.g., Chelton et al. $2000)$ or the "26-day variability" in the western equatorial Indian Ocean (e.g., Tsai et al. 1992; Kindle and Thompson 1989).

In section 2, we present the data sources and the new LMA approach (also see the appendix) used to extract the large-scale organized convective events and the associated variability in other fields (SST and surface wind). In section 3, we examine the spatial distribution of the ISV of the SST and its relationship to atmospheric forcing and the average mixed layer depth (MLD) and suggest a primary role of surface fluxes in the mixed layer temperature ISV. This is further tested by looking at the reddening of the SST ISV in two frequency bands using a simplified relation that considers the ISV of the atmospheric forcing and a climatological MLD. In section 4, we use the LMA approach to extract the SST response to large-scale organized convective intraseasonal perturbations and we discuss the mean patterns of the ISV covariability between the convection, the surface wind, and the SST. In section 5, we take advantage of the LMA method to analyze variations in the properties of this coupled variability from one intraseasonal event to another. Examining the delay between perturbations of the convection, the surface wind and the SST in particular make it possible to extract possible physical mechanisms for these SST perturbations at intraseasonal time scales. A summary and conclusion are given in section 6 .

\section{Analysis approach}

\section{a. Datasets}

The NOAA OLR dataset (Liebmann and Smith 1996) is used as a proxy to study the perturbation of the convective activity. Surface wind and surface net heat fluxes are taken from the National Centers for Environmental Prediction-Department of Energy (NCEPDOE) Atmospheric Model Intercomparison Project-II (AMIP-II) reanalysis (R2; Kanamitsu et al. 2002). We also use an MLD climatology (de Boyer Montégut et al. 2004) produced by objective analysis of individual profiles.
The intraseasonal perturbation of the SST is estimated using the TMI dataset (Wentz et al. 2000). The TMI instrument makes it possible to estimate the SST in cloudy conditions and is thus well adapted to studying the link between the convection and the SST. The orbital characteristics of TRMM, its swath, and missing SST estimates due to heavy rainfall, however, result each day in some data-void regions. To obtain full tropical $\left(38.5^{\circ} \mathrm{N}, 38.5^{\circ} \mathrm{S}\right)$ daily coverage, we have performed an interpolation by doing spatial filling and linear temporal interpolation from daily mean fields containing all the orbits projected onto a $1^{\circ} \times 1^{\circ}$ grid. Comparisons with in situ data done in DRV show that this product satisfactorily captures intraseasonal SST perturbations in the Indian Ocean during winter. Other studies (e.g., Sengupta et al. 2001) have shown that this product is well adapted to study intraseasonal SST variability linked to the convection. The shortcoming reported in Bhat et al. (2004) about the TMI SST (i.e., overestimated cooling for wind $>10 \mathrm{~m} \mathrm{~s}^{-1}$ ) tends to slightly overestimate the SST variability over some regions but does not modify the statistical phase relationship obtained later in this study.

The intraseasonal standard deviation of the SST in the 20-90-day band is reported for the TMI dataset and the Reynolds and Smith (1994) dataset for comparison (Fig. 1). Although similar patterns are apparent for both SST estimates, the amplitude of the intraseasonal variability given by the Reynolds and Smith (1994) dataset is notably smaller than the one measured by the TMI, especially in the near-equatorial region of the Indian Ocean. This is not surprising, since the Reynolds and Smith product is mostly based on measurements in the atmospheric infrared window for which the screening of clouds impairs the sampling of the SST variability (most likely the cold phase under convective clouds). Several comparisons with in situ data confirm that the Reynolds and Smith (1994) product underestimates the intraseasonal SST variability in the Indian Ocean and that TMI performs better (e.g., Sengupta and Ravichandran 2001; DRV). Since most previous statistical studies of the ISV of the SST related to convection used the Reynolds and Smith (1994) dataset, it is useful in this paper to reevaluate those results using the TMI dataset.

\section{b. The local mode analysis (LMA)}

The use of a complex empirical orthogonal functions (CEOF) is a straightforward approach for obtaining a single manageable pattern (i.e., one complex eigenvector) describing a quasiperiodic propagating perturbation such as the ISV. Since the ISV is also an intermittent phenomenon with large seasonal variation, the 

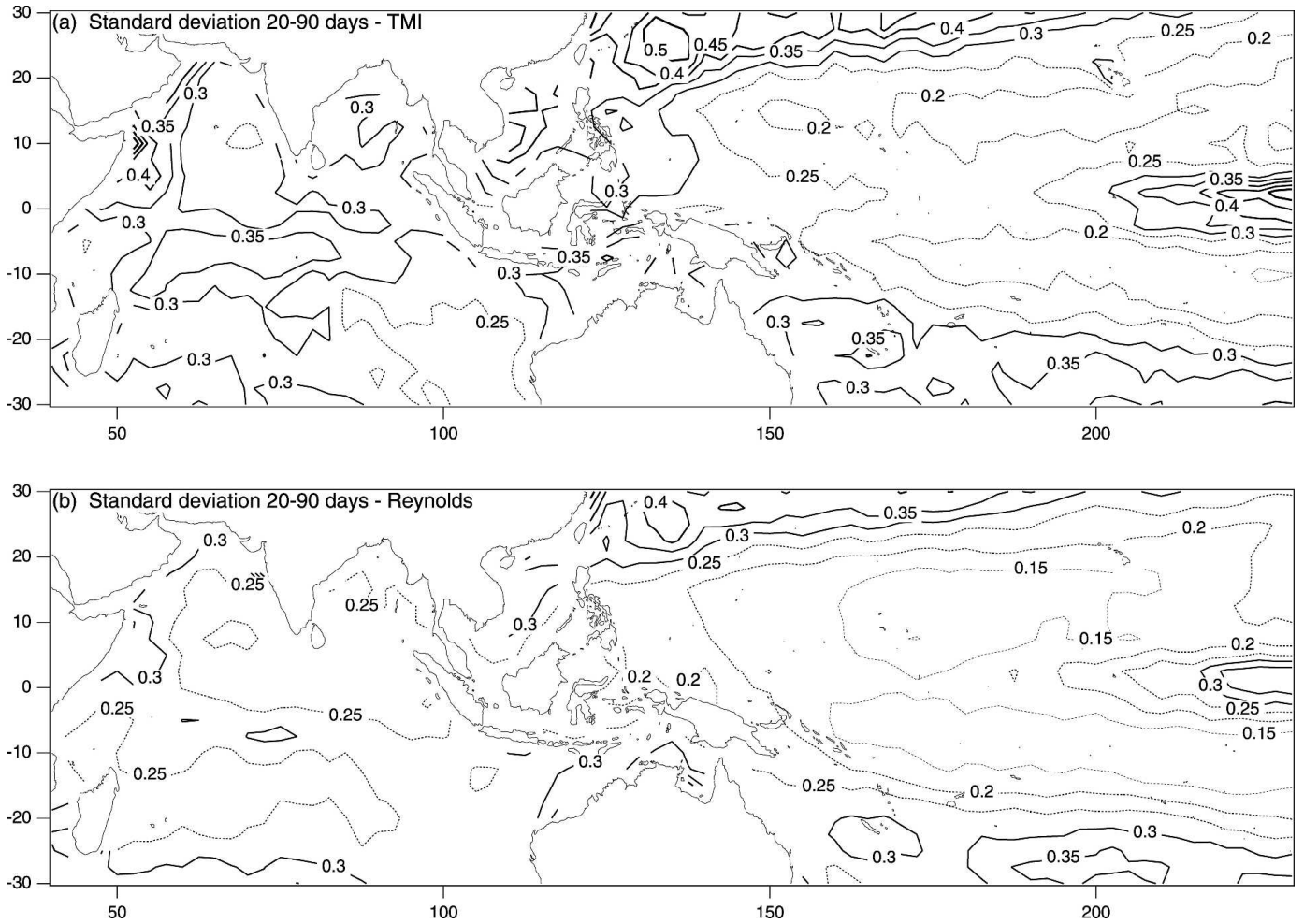

FIG. 1. Average standard deviation of the SST (K) in the 20-90-day band for the years 1998-2004 for (a) the TMI SST dataset and (b) the Reynolds and Smith SST dataset.

CEOF has to be applied on relatively short seasonal time series for which the ISV is supposed to be quite homogeneous (e.g., December-April). The first shortcoming of this approach is the end effect problem inherent in the use of spectral techniques on short time series. These end effects must be reduced by a windowing (i.e., Welch window) but this will truncate/reduce the signal toward the edge of the series and thus reduce perturbations at the beginning and the end of the selected season (the ISV perturbations do not necessarily append in midseason). Increasing the size of the window to overcome this problem however induces a risk of mixing between patterns characteristic of different seasons (which are not necessarily orthogonal and which appear on a single component). The second shortcoming of an average CEOF approach is that, even for a given season, the different ISV events do not necessarily have similar patterns. The pattern obtained from an average CEOF analysis is thus not necessarily representative of the different ISV events.

LMA (Goulet and Duvel 2000; Duvel et al. 2004) was designed to overcome these shortcomings. The technique is designed to perform CEOF analysis on a time section (120 days here), moving along the full time series with a small time step ( 5 days here). Local maxima of the percentage of variance explained by the CEOFs correspond to events that are well organized at large scales. Only the time sections centered on these events (the local modes) are then considered when constructing average patterns for a given season (see the appendix for the mathematical description of the method). This solves the first shortcoming due to the consideration of fixed calendar months or days for defining the time section. Also, since the LMA extracts a pattern for each event (i.e., each local mode), it is possible to measure the resemblance between an average pattern and the patterns of each ISV event and, thus, verify how this average pattern is representative of the various events in the considered time series.

The LMA technique is further developed in this paper in order to perform multivariate analysis. Using the CEOF approach, it is indeed possible to compute from one reference parameter (the OLR here) a complex eigenvector under the form of a normalized spectrum (i.e., a "spectral key"). The projection of the Fourier coefficients of all parameters (OLR, SST, and surface wind) on this normalized spectrum will give the associated patterns for those fields. These patterns thus represent SST and wind perturbations associated with large-scale organized perturbations of the convection (represented by the OLR). Using such an approach, it is also possible (see the appendix) to extract the pat- 

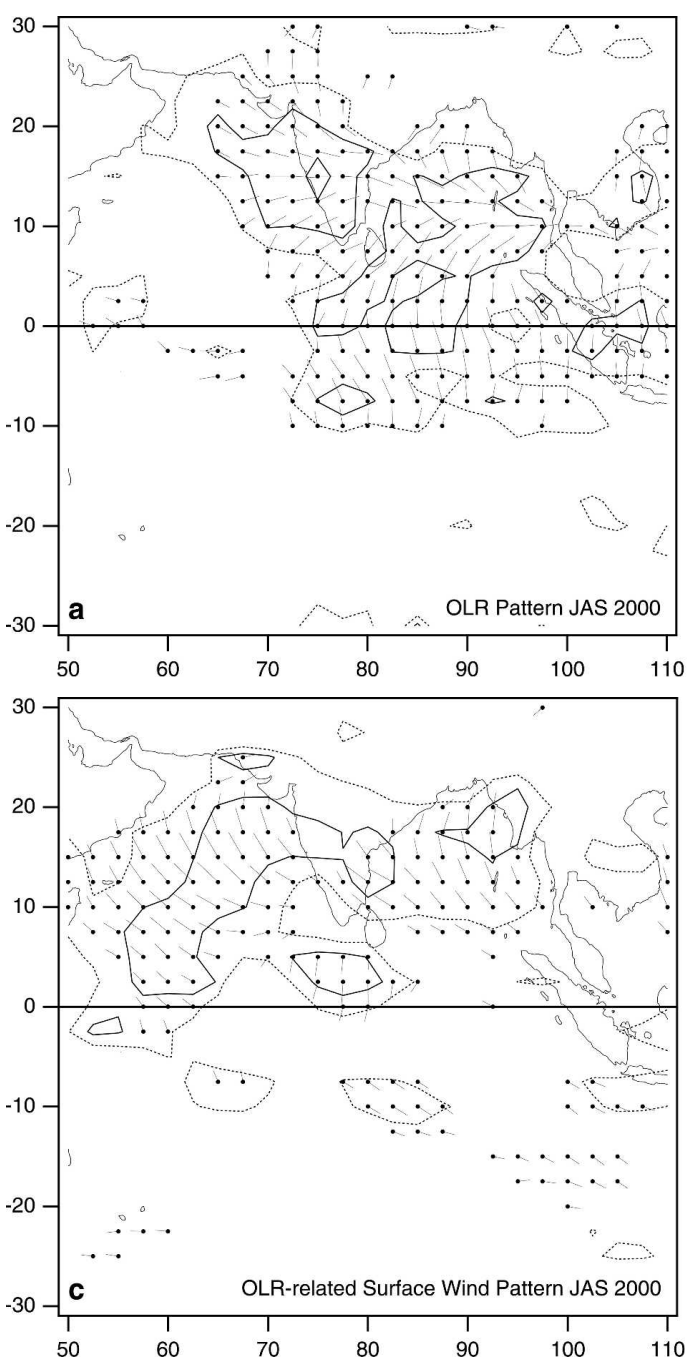

terns of the average responses of SST and wind to large-scale organized OLR intraseasonal perturbations (section 4). The LMA method provides a metric for comparing the average pattern to the patterns of individual events. Indeed, the LMA extracts the characteristics of the perturbations (e.g., time scale, phase lag between parameters, spatial patterns) for each event (section 5). This also makes it possible to study in detail the variability of the ISV events from one season (or one year) to another.

In the following, the LMA approach is used on the OLR, SST, and surface wind time series with a time window of 120 days. An analysis is performed every 5 days and only harmonics 1-6 are considered (i.e., $20 \leq T \leq 120$ ). Prior to the analysis, in order to remove low frequencies (mainly due to the seasonal cycle), harmonics 1-21 are removed from the full time series (2546 days between 12 December 1997 and 30 November 2004). For seasonal statistical analyses, a local mode is

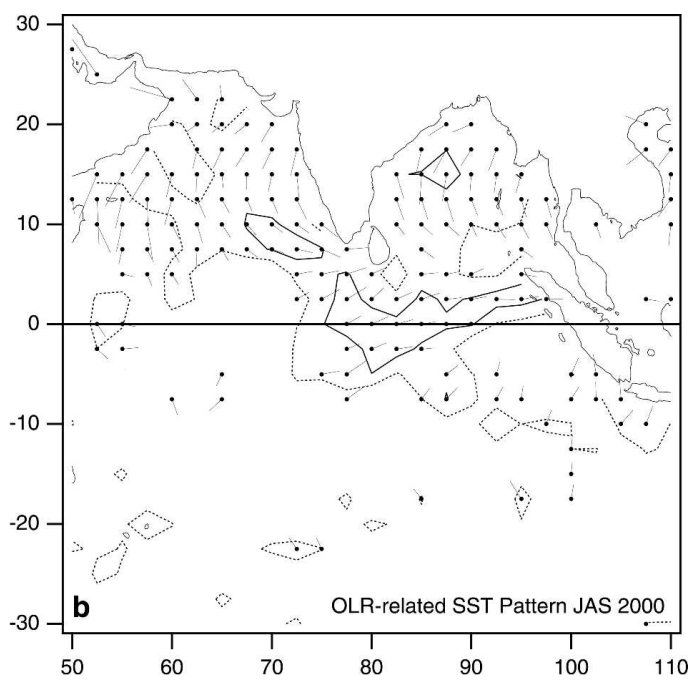

FIG. 2. Standard deviation $A_{p}^{m}(x)=\left|\tilde{Z}_{p}^{m}(x)\right|$ and relative phase $\phi_{p}^{m}(x)=\operatorname{Arg}\left[\tilde{Z}_{p}^{m}(x)\right]$ of the event extracted from the LMA for summer 2000 for (a) the OLR signal as the leading parameter, (b) the OLRrelated event for the SST, and (c) the OLR-related event for the surface wind. The length of the line at each plotted point (a segment) is proportional to the standard deviation and the angle of the segment represents the relative phase of the quasiperiodic signal. A relative phase difference of $\pi$ between regions or between parameters represents a lag of about 15 days between maxima. The angle increases clockwise with time (e.g., northward propagation for a segment rotating clockwise toward the north). The contour lines represent RRIs [Eqs. (A5) and (A8)] of 0.6 (dotted) and 0.8 (solid).

selected for a given month if the date of the center of its time section is in this month.

\section{c. Illustration of the multivariate LMA analysis}

An illustration of the LMA approach is given in Figs. 2 and 3 for a rather strong intraseasonal event during summer 2000 that was already analyzed in Vecchi and Harrison (2002). The event is a remarkable northward propagation of convective perturbations from $5^{\circ} \mathrm{S}$ to $20^{\circ} \mathrm{N}$ in the Bay of Bengal and in the eastern Arabian Sea (Fig. 2a). This northward propagation may be seen from the progressive shift of the relative phase of the $\tilde{Z}_{p}^{m}(x)$ between adjacent regions. This multivariate pattern is the most representative for the Bay of Bengal and the Arabian Sea, for which the regional representation index (RRI) is larger than 0.8 for the OLR, the SST, and the module of the surface wind. The delay between the minimum OLR (maximum convective activity) and the minimum SST is generally between $1 / 8$ 

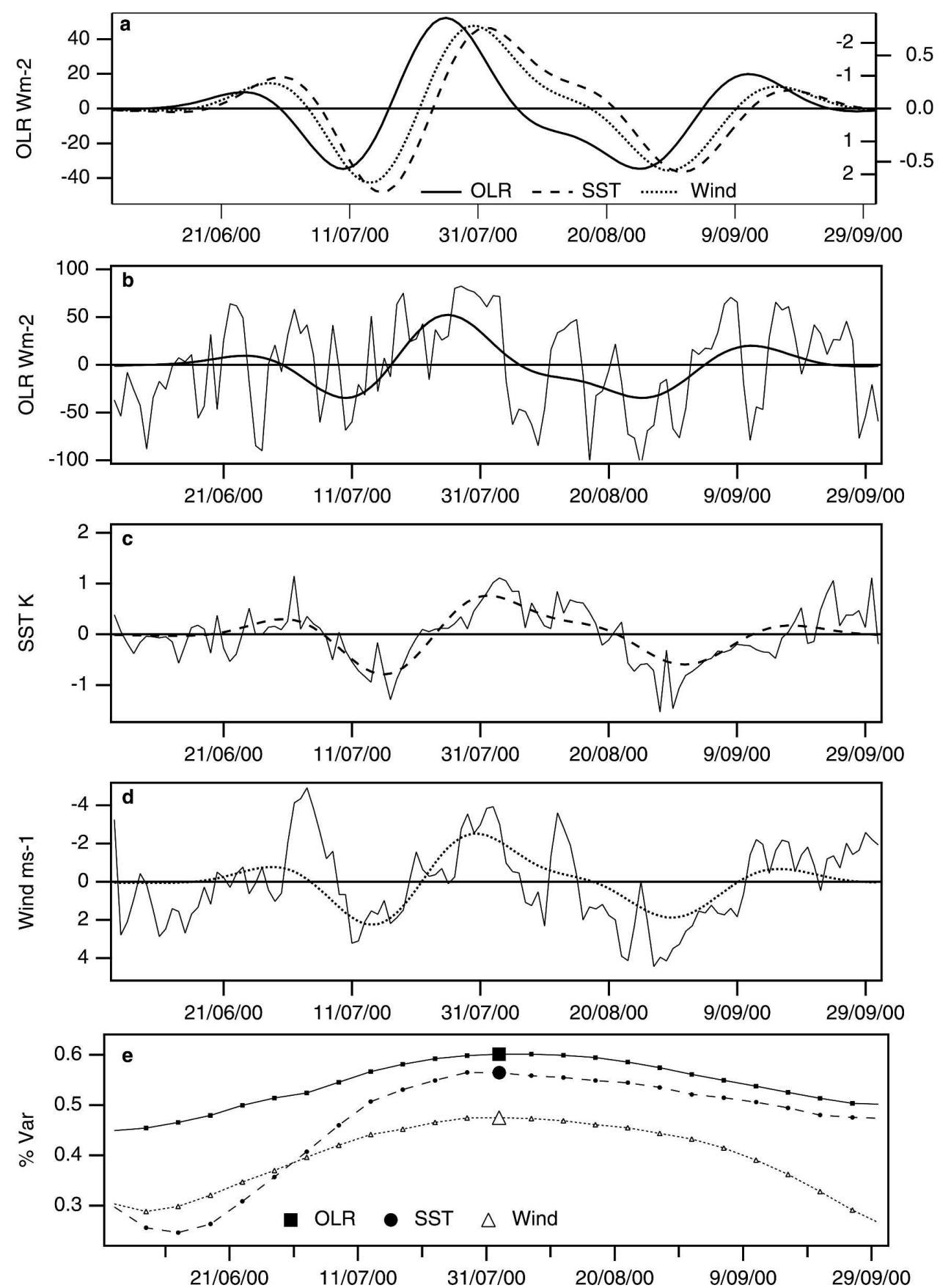

FIG. 3. (a) Reconstructed signals [Eq. (A4)] for the event shown in Fig. 2 and for the region near $15^{\circ} \mathrm{N}$, $87.5^{\circ} \mathrm{E}$, for the OLR (left axis in $\mathrm{W} \mathrm{m}^{-2}$ ), the SST (right axis in $\mathrm{K}$ ), and the surface wind (inside right axis in $\mathrm{m} \mathrm{s}^{-1}$ ). This reconstructed signal is superimposed on the raw signal (thin gray lines) for (b) OLR, (c) SST, and (d) surface wind. (e) Time evolution of the variance percentage [Eq. (A7)] for each time step $(m)$ and each parameter; the larger markers correspond to the local maximum of the variance percentage for the OLR (leading parameter) and thus to the central date of the time window for this local mode during summer 2000.

and $1 / 4$ of the period (i.e., 3.5-7 days). The OLRrelated surface wind perturbation is a maximum in the Arabian Sea and also in the Bay of Bengal. The delay between the maximum surface wind and the minimum
SST is smaller than $1 / 8$ of the period (i.e., 3.5 days) for most regions. For some regions in the center of the Bay of Bengal, the maximum surface wind is even simultaneous with the minimum SST. 
This is further illustrated in Fig. 3a by the reconstructed time series [Eq. (A4)] for a single $2.5^{\circ}$ region centered on $\left(15^{\circ} \mathrm{N}, 87.5^{\circ} \mathrm{E}\right)$ in the northern Bay of Bengal (the declining amplitude toward the limits of the time series is due to the Welch window). There are increases in the percentage of variance (Fig. 3e) in early July for both the SST and the surface wind, showing a strong reinforcement of the large-scale organized perturbations of these parameters in relation to the intraseasonal convective perturbation. These large-scale perturbations described by the patterns in Fig. 2, correspond, over the Bay of Bengal, to a maximum OLR (i.e., a monsoon break) near the end of July 2000 flanked by two convectively active periods. Locally, this break follows a positive wind anomaly and a negative SST anomaly that are generated by the convective perturbation in mid-July. During the break, the wind decreases and the SST rises. The development of the following convective phases in August 2000 is slower with a progressive strengthening of the surface winds and a cooling of the surface. This evolution of the perturbation is in good agreement with the analysis of Vecchi and Harrison (2002). It is interesting to notice that the apparently slow development of the convectively active phase is in fact related to a short break of 10 days around 15 August, associated locally with an interruption of the wind (Fig. 3d) and to a small positive perturbation of the surface temperature. There is indeed a relatively intense synoptic variability over this region of the Bay of Bengal with time scales of 4-10 days, even for the period of suppressed convection at lower frequency (Figs. 3b and 3d). However, only the slower ISVs of the convection and wind have significant effects on the SST (Fig. 3c) (which is consistent with the reddening of the ISV of the SST due to the ISV of the surface flux forcing studied in the next section).

This case study shows that, for a relatively short timesection selected by the LMA, the time series of the first CEOF is quite representative of the intraseasonal perturbation of the three parameters (the results in Fig. 3 are also valid for other regions). In particular, the phase difference between the ISV of the three parameters is described well by this local mode. By contrast, an average mode will give a single pattern for all events and the associated time series may not be adapted for a given region and event, giving potentially inaccurate phase relationships between parameters for a given region and event. The LMA thus makes it possible to analyze average patterns, which give a general view of the phenomenon, but also individual events that give the local characteristics that can be compared to the average pattern. By projecting the ISV of the SST onto
OLR local modes extracted by the LMA, the part of the SST variability related to the large-scale organized perturbation of the convection is extracted with no a priori assumption about the location of this convective perturbation.

\section{Average ISV of the SST and its link to atmospheric forcing and MLD}

\section{a. Average seasonal ISV of SST and atmospheric forcing}

As expected [see, e.g., Zhang and Dong (2004), the convection and the ISV of the convection are maximal south of the equator during January-March (JFM); see Fig. 4a]. The maximum ISV is generally located south of the ITCZ with minimum values over continental regions and islands. There is a strong ISV of the surface wind north of Australia in the Timor and Arafura Seas and in the Gulf of Carpentaria with a stronger variability (both in wind and convection) over the ocean compared to the adjacent Australian continent. The ISV of the SST is particularly strong north of Australia and also in the $5^{\circ}-10^{\circ} \mathrm{S}$ band in the western and central Indian Ocean. There is no obvious collocation between the maximum ISV of the OLR (also a proxy for the solar heat flux perturbation), the surface wind (a proxy for turbulent heat flux perturbation and for subsurface cooling due to vertical mixing), and SST, except north of Australia.

In JJA, the ISV of the convection is also maximal on the edge of the ITCZ, suggesting that the ISV plays an important role in the extension of the convective activity around the main centers of instability. In the Indian Ocean, maximum convection is found over the northeastern Bay of Bengal (contours in Fig. 4e) and maximum ISV of the convection is located around the Indian subcontinent (with a relative minimum on continental regions) and near the equator east of $70^{\circ} \mathrm{E}$. The ISV of the surface wind is maximal in the northwest Pacific Ocean and there are two secondary maxima: in the Bay of Bengal and in the Arabian Sea. The ISV of the SST is strong north of the Bay of Bengal and on the Arabian coast. The Arabian coast is an upwelling area known for strong eddy activity, which may explain part of this variability. The region of strong ISV of the SST north of the equator in the central Pacific is also due to oceanic internal variability [tropical instability waves; see, e.g., Chelton et al. (2000)]. The largest ISV of the SST is obtained in the western Pacific north of $20^{\circ} \mathrm{N}$.

These quite complex patterns for both the summer and winter seasons show that the interaction between the OLR and the SST at intraseasonal time scales is not 

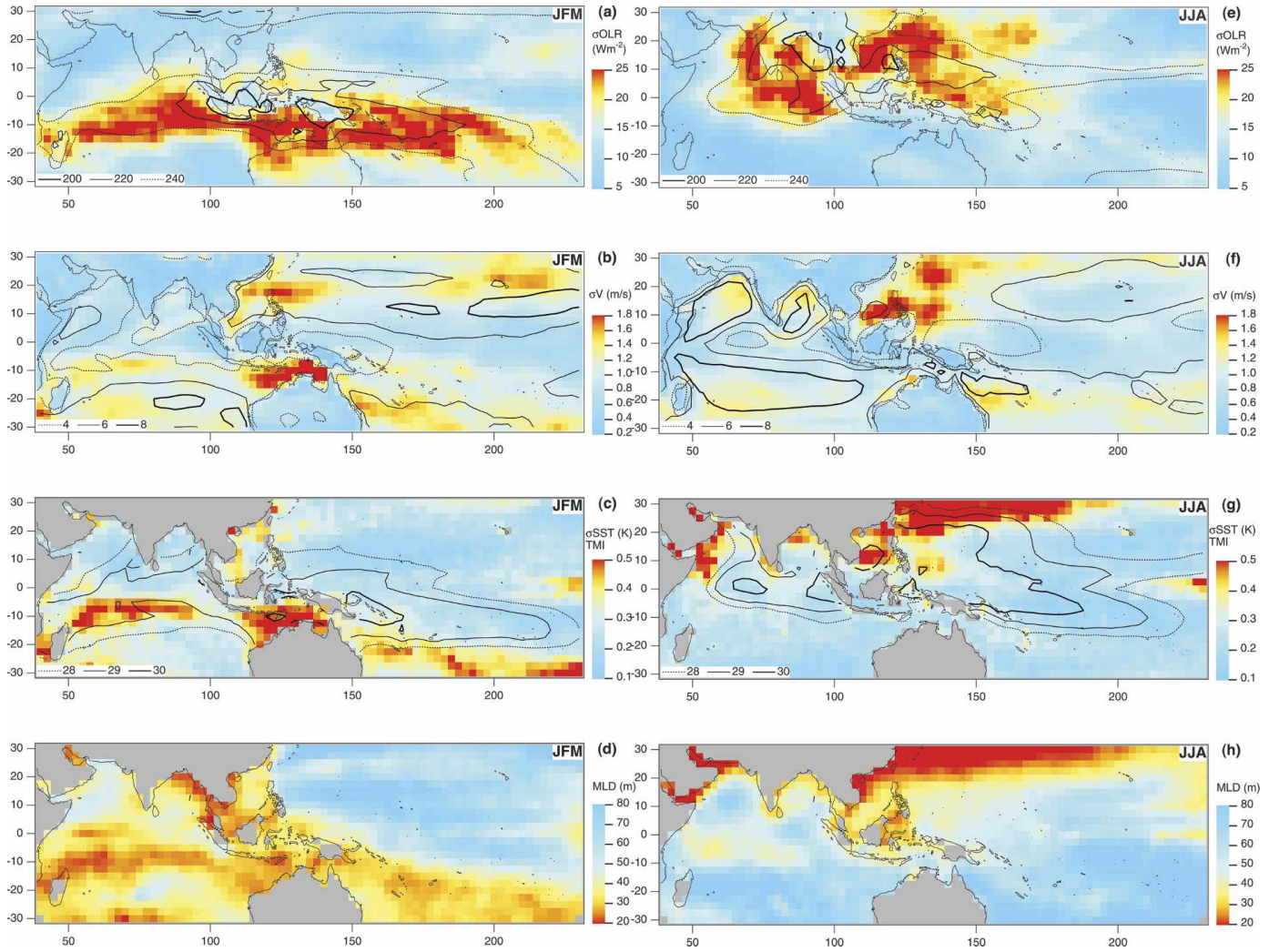

FIG. 4. Seasonal [(left) JFM, (right) JJA] average (contours) and 20-90-day-band standard deviation (colors) for (a),(e) the NOAA OLR, (b),(f) the NCEP surface wind module, and (c),(g) the TMI SST. (d),(h) The seasonal average of the mixed layer depth from the de Boyer Montégut (2004) climatology.

only related to the local perturbation of the surface fluxes by the convective systems. One must certainly consider the depth of the ocean mixed layer, as shown in the following section, and the response of the surface wind to the large-scale convective perturbation that perturbs the surface fluxes even in remote regions. The existence or abscence of both local and remote perturbations of the surface fluxes over the same region and the time lag between these perturbations will have an obvious impact on the final amplitude of the SST perturbation.

\section{b. Mixed layer depth and the intraseasonal SST variability}

A large part of the intraseasonal variability of the SST is expected to be related to perturbations of the average mixed layer temperature (another part being related to the formation of warm layers as discussed in DRV). This average mixed layer temperature varies following the equation derived from the heat conservation equation integrated vertically over the MLD (see, e.g., Duvel et al. 2004):

$$
\begin{aligned}
\partial_{t} T= & \frac{Q^{*}+Q_{S}[1-f(-H)]}{\rho_{0} C_{P} H}+\frac{E_{-H}}{\rho_{0} C_{P} H} \\
& -u \partial_{x} T-v \partial_{y} T+D .
\end{aligned}
$$

The first term of Eq. (1) represents the heat flux forcing $\left[Q_{S}\right.$ is the net surface solar heat flux, $Q^{*}$ is the nonsolar part of the heat flux, $f(-H)$ is the fraction of the solar radiation that penetrates down to the depth $H$ of the mixed layer, and $\rho_{0} C_{P}$ is the volumetric heat capacity of seawater $\left.\left(4 \times 10^{6} \mathrm{~J} \mathrm{~K}^{-1} \mathrm{~m}^{-3}\right)\right]$. The second term is the effect of the interior ocean $\left(E_{-H}\right.$ is the heat flux at the bottom of the mixed layer, which is a combination of entrainment, vertical mixing, and the effect of the vertical current). The two following terms are the zonal and meridional advections of the mean mixed layer currents. The last term stands for the (usually small) effects of current vertical shear in the mixed layer and the effects of lateral eddy heat flux convergence.

In this equation, $H$ is thus a key factor controlling the reactivity of the mixed layer temperature to either surface heat fluxes or heat exchange at its bottom. Outside 
the equatorial zone, these bottom exchanges are mostly cooling related to surface forcing, either dynamically via wind stress or thermodynamically by the generation of negative buoyancy in the surface layer. The vertical current term will also be forced in part by Ekman pumping generated by the surface wind stress.

Without precise information on the variability of the mixed layer structure, it is difficult to quantify the role of the different physical processes of (1) in the ISV of the SST. However, as a first approach, the influence of the MLD on the intraseasonal variability of the SST may be investigated by comparing average maps of the MLD and the intraseasonal variability of the SST for winter (JFM; Figs. 4c and 4d) and summer (JJA; Figs. $4 \mathrm{~g}$ and $4 \mathrm{~h})$. These maps are indeed remarkably similar with generally a maximum SST ISV for small values of the MLD. This suggests that the first two terms in (1) represent essential processes for the ISV of the SST. A striking feature is the band of strong intraseasonal variability between $5^{\circ}$ and $10^{\circ} \mathrm{S}$ in the Indian Ocean in JFM in a thin $(20-30 \mathrm{~m})$ region of the mixed layer, which is consistent with the two events studied in detail in Duvel et al. (2004). Also, the region of large ISV of the SST below the South Pacific convergence zone (SPCZ) is associated with a 20-30-m mixed layer. During the summer, the regions of strongest ISV of the SST correspond to thin mixed layers such as in the South China Sea, in the western Pacific subtropics, in the northern Bay of Bengal, and in the western Arabian Sea. This qualitative assessment is confirmed by the rather high $(0.67$ for JFM and 0.74 for JJA) linear correlation coefficients between maps of the ISV of the SST and the inverse of the climatological MLD. This result shows, in addition, that the MLD climatology is apparently sufficiently robust to represent the broad seasonal distribution of the MLD for the 1997-2004 period.

This suggests that the first two terms in (1) represent a main source of ISV for the SST. This is in good agreement with previous studies (e.g., Jones et al. 1998; Shinoda et al. 1998, Woolnough et al. 2000; Duvel et al. 2004) showing that the first term, that is, the effect of the net surface heat flux, is the dominant term in the ISV of the SST. For regions with an ISV controlled primarily by this first term, one may expect good correlation between the derivative of the SST and the net surface heat flux forcing. These regions are identified in the following by computing such a correlation in two spectral bands by using the net surface flux provided by NCEP-National Center for Atmospheric Research (NCAR) reanalyses. We thus consider that the net surface fluxes given by the NCEP-NCAR reanalyses are precise enough to give the correct intraseasonal phase and amplitude. This hypothesis is somewhat justified a posteriori by the significant correlation obtained in the 30-90-day band (Figs. 5a and 5c) and in the 20-30-day band (Figs. 5b and 5d). These two intraseasonal bands correspond to the same number of harmonics of our time series of 2546 points, 49 harmonics for the 30-90day band (29-78) and for the 20-30-day band (79-128). This gives 96 degrees of freedom for the whole time series, and thus 24 for the JFM seasons, and a correlation of 0.5 is thus significant at the $99 \%$ confidence level. The correlation is indeed larger than 0.5 for most regions of the summer hemisphere. For these regions, an additional diagnostic can be performed to quantify the potential role of the first rhs term in (1) in the ISV of the SST. If this role is important, the variability of the SST can be approximated by a simplified relation:

$$
\partial_{t} T=\frac{Q}{\rho_{0} C_{P} H},
$$

where $Q$ represents the net surface fluxes. In the following, the depth $H$ of the mixed layer is taken from the seasonal value of the de Boyer Montégut et al. (2004) climatology (Figs. 4d and 4h). We thus consider that interannual and intraseasonal variabilities of the MLD have only a slight impact on the general correlation. This last point is certainly incorrect in the highly reactive equatorial region but may be considered acceptable in other regions, as shown in Duvel et al. (2004) for the Indian Ocean during $\mathrm{NH}$ winter. For a pulsation $\omega$, (2) becomes

$$
\partial_{t} T=\frac{\sqrt{2} \sigma_{Q}^{\omega} \cos (\omega t)}{\rho_{0} C_{P} H},
$$

where $\sigma_{Q}^{\omega}$ is the standard deviation of $Q$ for this spectral band. Integrating (3), the standard deviation of the SST variability induced by the forcing at pulsation $\omega$ is

$$
\sigma_{T}^{\omega}=\frac{\sigma_{Q}^{\omega}}{\rho_{0} C_{P} H \omega} .
$$

The regions for which the first term of (1) is the main processes of the intraseasonal variability should thus verify (4). As reported in Hasselmann (1976), the presence of the pulsation $\omega$ at the denominator in (4) translates the variance toward low frequencies, producing a reddening of the spectrum. This reddening can be verified by estimating $\sigma_{T}^{\omega}$ and $\sigma_{Q}^{\omega}$ from the TMI and NCEP datasets, respectively. Based on (4), a linear relation $\sigma_{T}^{\omega}=c_{\omega} \sigma_{Q}^{\omega} / H+n$ is expected between $\sigma_{T}^{\omega}$ and $\sigma_{Q}^{\omega} / H$ for a given $\omega$ with a corresponding characteristic time scale of $\tau=2 \pi \rho_{0} C_{P} C_{\omega}$. The constant $\mathrm{n}$ represents the SST variability due to sources independent of the surface flux. The linear shape of the relation between $\sigma_{T}^{\omega}$ and $\sigma_{Q}^{\omega} / H$ for two different frequency bands appears to be quite robust, after taking into account the use of 

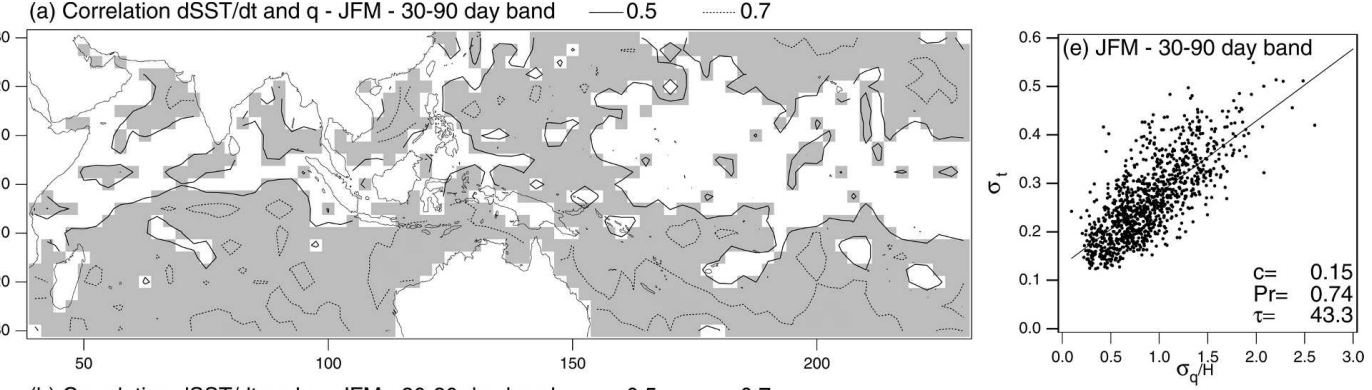

(b) Correlation dSST/dt and q - JFM - 20-30 day band $-0.5 \quad 0.7$
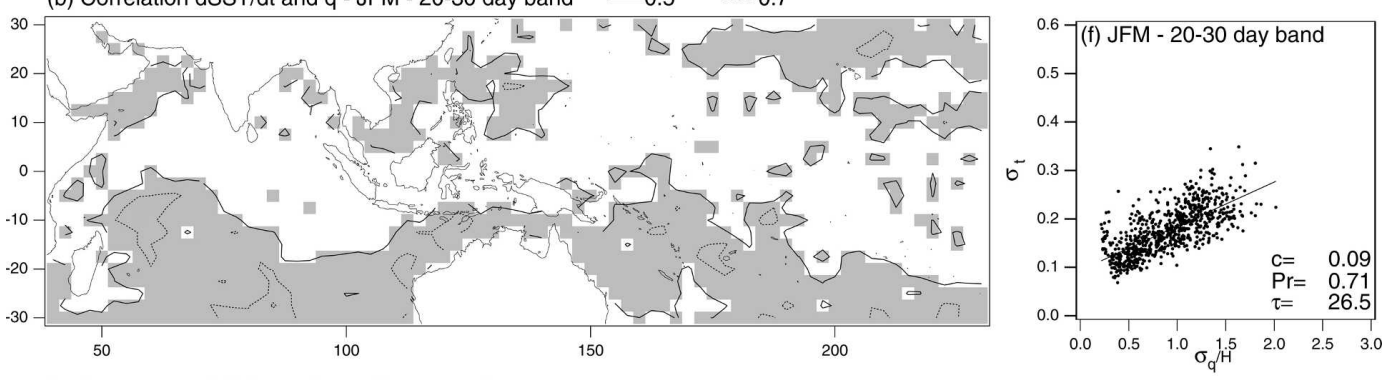

(c) Correlation dSST/dt and q - JJA - 30-90 day band $\quad-0.5 \quad 0.7$
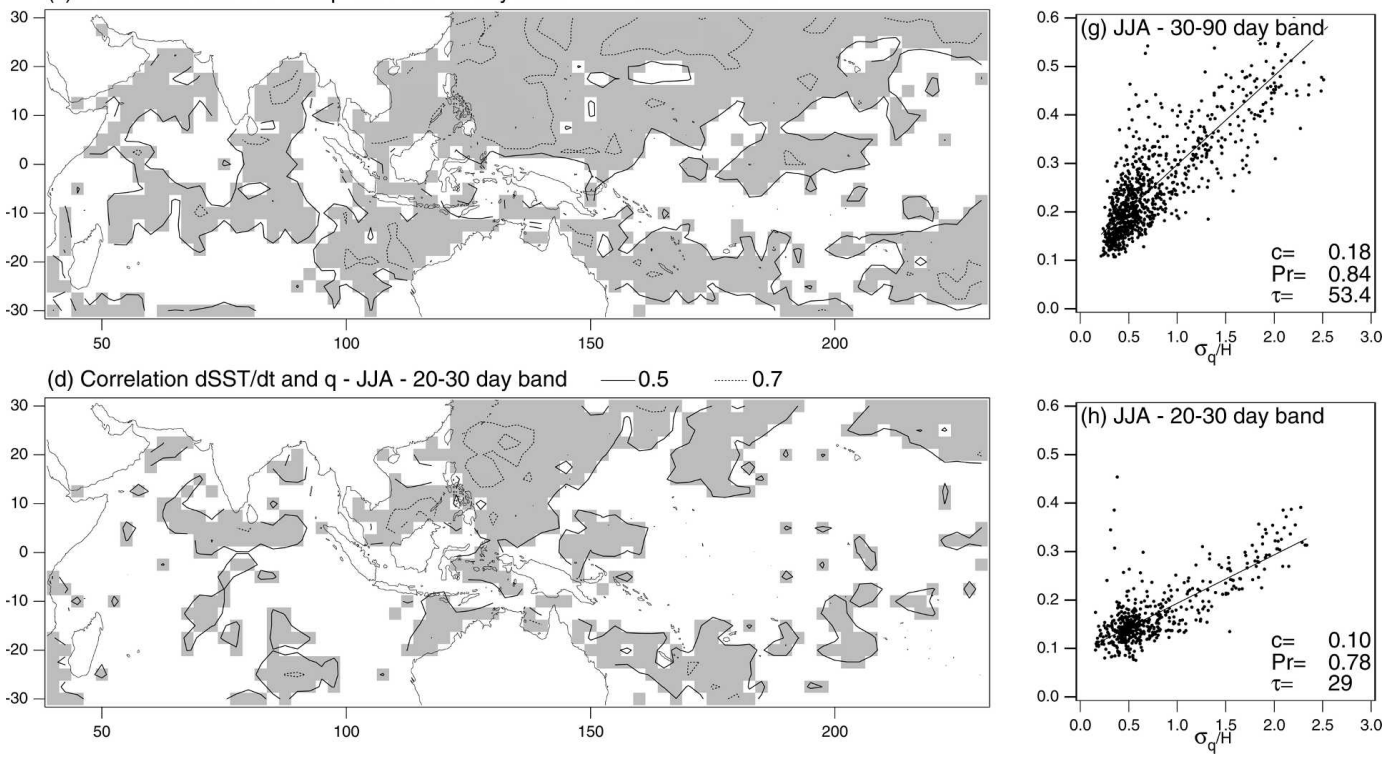

FIG. 5. (left) Correlation between the derivative of the TMI SST and the NCEP net surface fluxes for (a) the 30-90-day band in JFM, (b) the 20-30-day band in JFM, (c) the 30-90-day band in JJA, and (d) the 20-30-day band in JJA; solid contours represent a correlation of 0.5 and dashed contours one of 0.7. (right) Scatter diagrams for regions with a correlation coefficient larger than 0.5 between $\sigma_{T}^{\omega}$ and $\sigma_{Q}^{\omega} / H$, and linear regression line for (e) the 30-90-day band in JFM, (f) the 20-30-day band in JFM, (g) the 30-90-day band in JJA, and (h) the 20-30-day band in JJA. The value of the line slope $c$, the corresponding time scale $(\tau)$, and the linear correlation coefficient $(\operatorname{Pr})$ are also indicated in (e)-(h).

completely independent datasets. In the 20-30-day band, the time scale $\tau$ estimated from the linear regression is 26.5 days for JFM (Fig. 5f) and 29 days for JJA (Fig. 5h). In the 30-90-day band, it is 43.3 days for JFM (Fig. 5e) and 53.4 days for JJA (Fig. 5g). The good consistency between the period $\tau$ deduced from the slope $c_{\omega}$ and the input spectral domain of $\sigma_{T}^{\omega}$ and $\sigma_{Q}^{\omega}$ confirms the statistical reddening of the SST spectrum, which is consistent with a mixed layer integrating the surface flux variabilities for the considered regions. This is consistent with the hypothesis that for most regions of the summer hemisphere, the surface fluxes are statistically a leading source of SST variability at intraseasonal time scales. However, as shown by the dispersion of the scatter diagrams in Fig. 5, this statistical relation does not preclude other atmospheric-driven 
processes-like turbulent mixing at the mixed layer bottom, formation of warm layers, or Ekman pumping-from also playing a role in the ISV of the SST.

The above estimates of the ISV of the SST and wind did not isolate the part that is specifically linked to large-scale organized ISV of the convection (like the MJO during $\mathrm{NH}$ winter). In the Indo-Pacific region, a large part of the intraseasonal forcing is indeed due to a succession of quasiperiodic events that will strongly organize the ISV of the whole coupled system (in this case the reddening for a quasiperiodic event will slightly translate the amplitude of the peak in the SST spectrum toward lower frequencies.) For this organized ISV, the formation of warm layers and/or Ekman pumping may play a more important role in the perturbation of the SST. Extracting these organized intraseasonal perturbations will thus give more information on the origin of the ISV of the SST and on its potential feedback on the atmosphere. The ISV is however an intermittent phenomenon and, as shown in the previous section, one must build the relation between the SST and the OLR on an index based on the large-scale organization of the convection rather than only on the local OLR perturbation. To understand the physical source of the intraseasonal SST response, it is thus certainly adapted to use an approach such as the multivariate LMA. This makes it possible to extract the SST and wind perturbations for each intraseasonal event as a function of the OLR large-scale organized perturbations.

\section{ISV of the SST associated with large-scale organized convective perturbations}

As shown in Goulet and Duvel (2000), seasonal average patterns for the whole Indo-Pacific area are poorly representative of individual events, especially during boreal summer. Thus, while some intraseasonal events are well organized over the whole Indo-Pacific region, there are also a variety of events that are organized only at a basin scale. In addition, we are interested here mostly in the relation between the convection, the surface wind, and the SST, and not by the interbasin structure of the convective perturbations. The large-scale organized convective events are thus detected here by applying the LMA separately for the Indian Ocean $\left(30^{\circ} \mathrm{S}-30^{\circ} \mathrm{N}, 50^{\circ}-110^{\circ} \mathrm{E}\right)$, the Maritime Continent $\left(30^{\circ} \mathrm{S}-30^{\circ} \mathrm{N}, 100^{\circ}-160^{\circ} \mathrm{E}\right)$, or the western $\mathrm{Pa}-$ cific $\left(30^{\circ} \mathrm{S}-30^{\circ} \mathrm{N}, 150^{\circ}-210^{\circ} \mathrm{E}\right)$.

The NCEP radiative surface fluxes are not used here because we prefer to rely on the observed OLR as a proxy for the phasing between the SST and the solar flux perturbation due to deep convection. Also, the NCEP surface winds are used instead of the surface turbulent fluxes in order to have more direct information on the other potential role of the winds in SST perturbations related, for example, to upwelling, mixing with subsurface water, or warm layer formation. The analysis of the phase relation between the OLR, the surface wind, and SST can reveal information about the processes at work. For example, if convection and wind perturbations are in phase, one expects a 1/4period lag of the SST with respect to these perturbations if the surface fluxes are the dominant process. The phase relation between the wind and the SST due to other processes is however more variable with regard to the 1/4-period lag related to the simple integration of surface fluxes by a mixed layer with constant depth. For example, in the presence of a warm layer prior to the convective perturbation, the daily mean SST will tend to be maximal for the minimum wind and will sharply decrease toward the average mixed layer temperature as soon as the wind rises above a given threshold. Even if the mixed layer temperature then evolves under the forcing of surface fluxes, the phase relationship between wind and SST will be modified by this warm layer formation/destruction with the phase of the SST becoming more opposite to the surface wind.

\section{a. Indian Ocean}

Some characteristics of the OLR intraseasonal events detected over the Indian Ocean area are first shown in Fig. 6. There is a clear seasonal variation of the average standard deviation (Fig. 6a) of the events with minimum values for the few events around the equinoxes. The standard deviation of the local modes is maximal in January and May. A striking feature is the block of strong events in May that are quite separated from a block of events during mid-June to mid-August (there is no event detected in September). For the NH summer months, we will thus separately examine May as corresponding to the season of preonset and "bogus" onset (Flatau et al. 2001) and JJA as corresponding to the core months of the monsoon. The average patterns are thus computed for 7 events in JFM, 10 events in JJA, and 6 events in May. There are in fact two very similar events in May 2004 (due to the particular time evolution of the variance percentage) but the redundant local mode is nevertheless conserved since it does not significantly change the average results (not shown).

Since the ISV is not purely harmonic, the "period" of an ISV event is not perfectly defined. We use here the procedure proposed in Goulet and Duvel (2000) to compute an "average time scale" from a sum of phase differences between two time steps weighted by their average amplitude. This is done for the time series cor- 

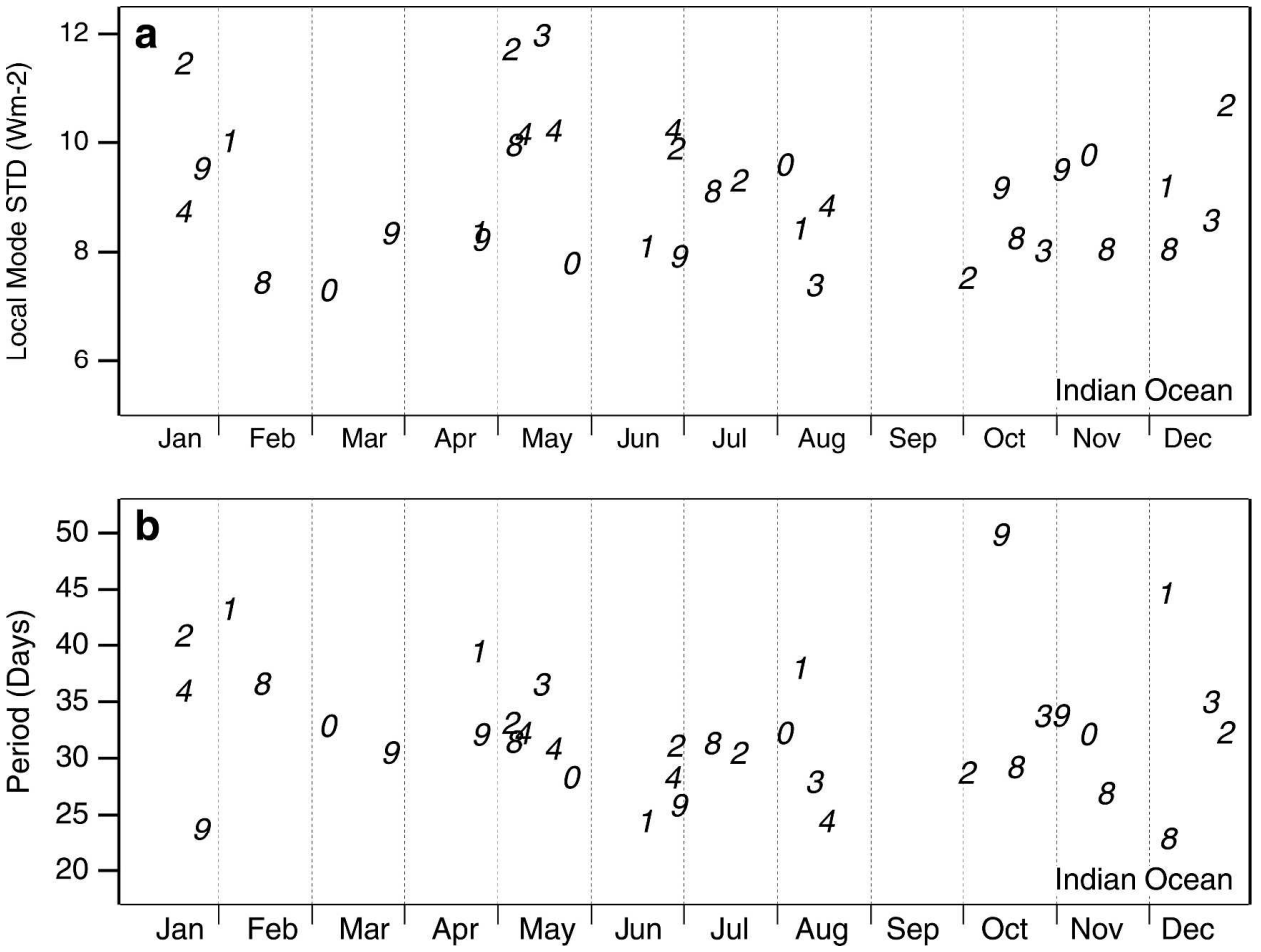

FIG. 6. Monthly statistics of the intraseasonal events over the Indian Ocean area for (a) the average standard deviation of the local modes and (b) the average time scale (or period) of each local mode. The numbers for each month represent the last digit of the year between 199(8) and 200(4) of each event.

responding to the spectrum $\tilde{\psi}_{p}^{m}(k)$. After careful examination of different events, a good approximation for the "period" of an event appears to be this average time scale diminished by its standard deviation (this diminution is needed because the first harmonics considered120 and 90 days - tend to overestimate the average time scale). The resulting period reported in Fig. $6 \mathrm{~b}$ confirms a weak tendency already highlighted in Goulet and $\mathrm{Du}-$ vel (2000) for a shorter time scale during NH summer. The two events of NH winter 1999 already studied in Harrison and Vecchi (2001) and DRV have relatively short periods compared to other winter events, particularly for the January 1999 event.

For JFM, the average OLR pattern (cf. the Appendix, section c; see also Fig. 7a) represents a typical eastward-propagating perturbation with a phase speed of around $6^{\circ}$ day $^{-1}$ for an average time scale of 35 days (Fig. 6b). The maximum OLR amplitude is located south of the equator over the eastern Indian Ocean. The associated SST perturbation (Fig. 7b) is also maximal south of the equator with maximum amplitude over the central Indian Ocean at $7.5^{\circ} \mathrm{S}$. There is an eastward propagation of this SST perturbation with a relative phase lag of $1 / 8$ to $1 / 4$ of a period with regard to the OLR (Fig. 8a). There is also an equatorward propagation of the SST anomaly (Fig. 7b) and the surface wind
(Fig. 7c), giving a slightly longer delay (1/4 of a period) between the maximum convection and the minimum SST near the equator (Fig. 8a). The associated surface wind perturbation is maximal over the western Indian Ocean south of the equator (Fig. 7c). The maximum perturbation occurs less than $1 / 8$ of a period before the minimum SST and is even simultaneous with the minimum SST for regions near the equator (Fig. 8b). In regions of large SST perturbation near $7.5^{\circ} \mathrm{S}$, the wind perturbation is maximal just after the convective maximum (Fig. 8c). This delay between the wind maximum and the convection tends to be larger near the equator and over the eastern Indian Ocean. For a Gill-type dynamical response to convective warming (Gill 1980), the maximum wind perturbation (mostly westerly wind) is expected to be west of the convective maximum. This will introduce a lag between the convection and the wind perturbations for an eastward-moving perturbation. In addition, Fig. 7 shows that for the three seasons, the average ISV of the surface wind is shifted to the west with regard to the maximum OLR perturbation. This is also in agreement with a (mainly zonal) surface wind perturbation associated with a Gill-type dynamical response.

In May, the organized convective perturbation is maximal south of the Bay of Bengal (Fig. 7d). The av- 

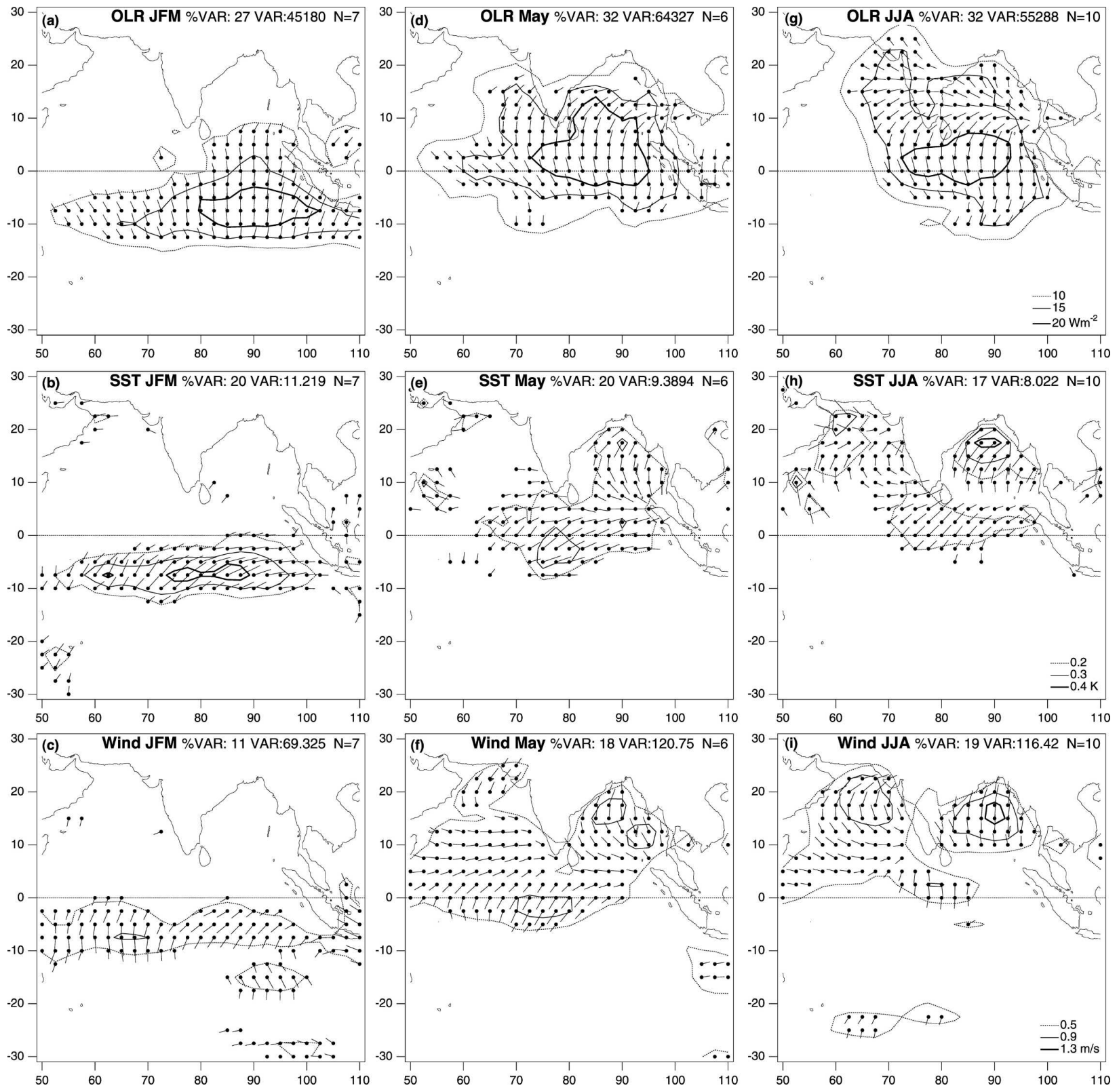

FIG. 7. Multivariate average pattern of intraseasonal variation of the (top) OLR, (middle) SST, and (bottom) surface wind for, from left to right, JFM (7 events), May (6 events), and JJA (10 events). The corresponding variance percentages for each parameter are reported in (a)-(c). As in Fig. 2, the segment length is proportional to the standard deviation and the angle of the segment represents the relative phase. The angle increases clockwise with time (e.g., northward propagation for a segment rotating clockwise toward the north). The contour lines represent the standard deviation of these average patterns and the values of the contour lines are given at the bottom of $(\mathrm{g})-(\mathrm{i})$.

erage pattern is a northward propagation with a phase speed of around $2^{\circ}$ day $^{-1}$, superimposed to an eastward propagation with a propagation speed of $4^{\circ}-5^{\circ}$ day $^{-1}$. The corresponding wind and SST perturbations are maximal south of the tip of India and over the Bay of Bengal (Figs. 7e and 7f), in agreement with the bogus onsets described in Flatau et al. (2001). For most re- gions, the SST is minimal $1 / 4$ of a period after the maximum convection (Fig. 8d) and nearly simultaneous with the maximum surface wind (Fig. 8e). Here, the wind is thus maximum $1 / 4$ of a period after the maximum convection (Fig. 8f).

In JJA, the most striking difference compared to May is the stronger perturbation of the convection be- 


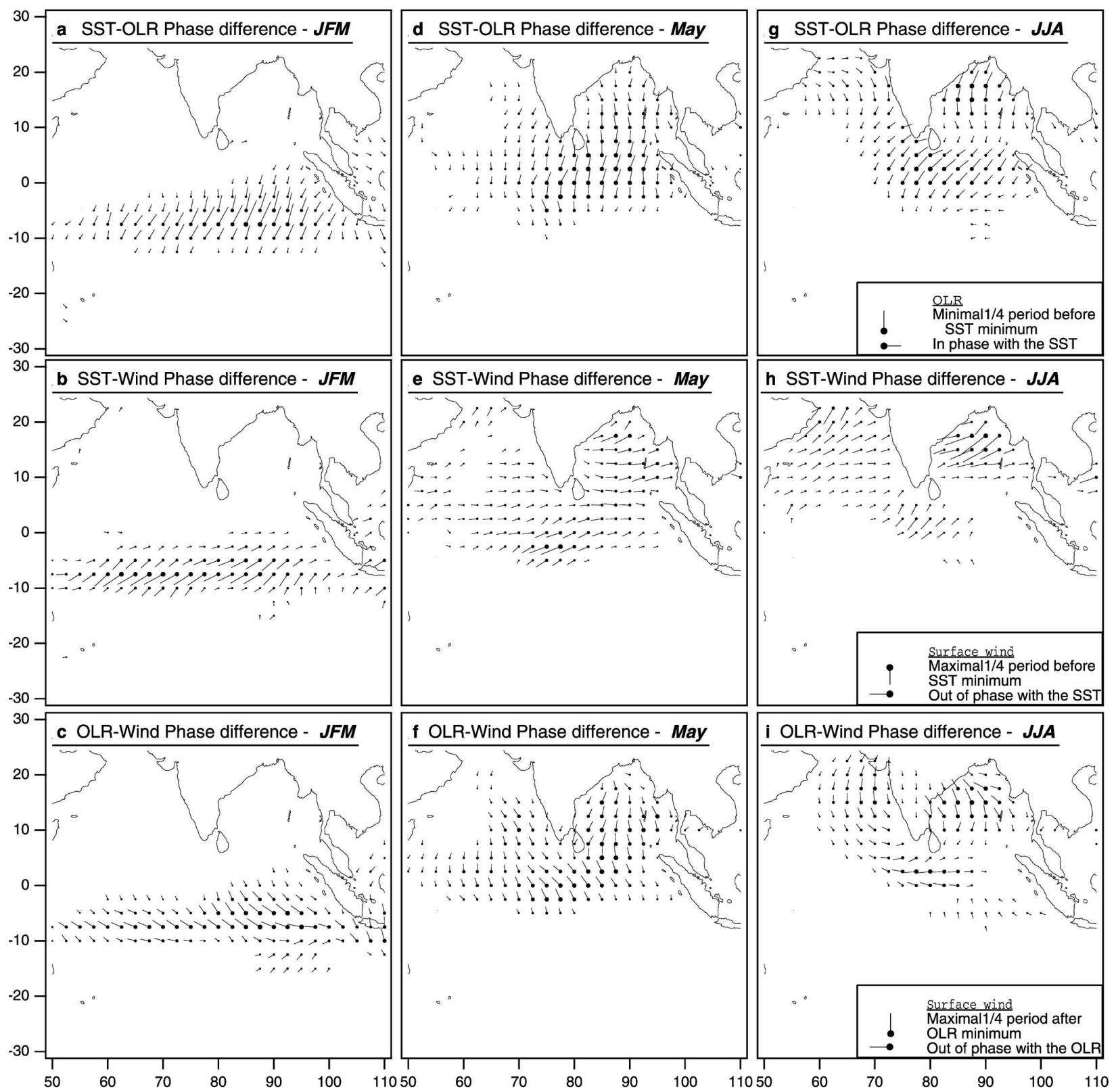

FIG. 8. Phase differences between the SST perturbation and the (top) OLR and (middle) surface wind, and (bottom) between the OLR and the surface wind for (left) JFM, (middle) May, and (right) JJA. For the top figures, a northward (eastward) pointing segment means that the OLR is at a minimum $1 / 4$ of a period before (simultaneous with) the minimum SST. For the middle row, a southward (westward) pointing segment means that the surface wind is at a maximum $1 / 4$ of a period before (simultaneous with) the minimum SST. For the bottom graphs, a northward (westward) pointing segment means that the surface wind is at a maximum 1/4 of a period after (simultaneous with) the minimum OLR. The segment length is proportional to the product of the normalized standard deviations of both parameters considered.

tween $10^{\circ}$ and $25^{\circ} \mathrm{N}$ over the Indian subcontinent and the eastern Arabian Sea (Fig. 7g) related to enhanced perturbations for both the SST and surface wind (Figs. $7 \mathrm{~h}$ and $7 \mathrm{i})$. The SST amplitude is maximal northwest of the Arabian Sea over regions of small MLD (Fig. 4h). The OLR amplitude over the northwest Arabian Sea is weak, suggesting that the ISV of the SST is rather due to the surface wind perturbations associated with the ISV of the convection farther east. According to results reported in Joseph and Sijikumar (2004), there are indeed intraseasonal perturbations of the low-level wind over the Arabian Sea associated with convection over 
the Bay of Bengal (see their Figs. 5 and 6). Near the coast of Oman, the SST and wind perturbations tend to propagate northward more slowly (around $0.6^{\circ}$ day $^{-1}$ ) north of $15^{\circ} \mathrm{N}$ over the Arabian Sea but keep their phase difference of about $1 / 8$ of a period (Fig. 8h). The SST perturbation there might be linked to a modulation of the upwelling by the local wind perturbation.

There are also relatively large perturbations of the SST and surface wind south of the tip of India and north of the Bay of Bengal (Figs. 7h and 7i). This is related to a phase opposition of the perturbations between these two regions. This phase opposition is more striking for the SST and the surface wind, and well underlined by the absence of variability around $7.5^{\circ} \mathrm{N}$. Near the equator, the maximum surface wind and convective activity precede the minimum SST by about $1 / 4$ of a period (Figs. $8 \mathrm{~g}$ and $8 \mathrm{~h}$ ). For the northern Bay of Bengal, the surface wind is a maximum during or just before the minimum SST. This feature is also well illustrated for the summer mode of 2000 (Figs. 2 and 3), which also shows the good reproducibility of this multivariate pattern. Near the equator, the wind is maximal during the convective event (Fig. 8i), in agreement with the relatively large SST perturbation despite the thick mixed layer (Fig. 4h). The wind perturbation over the eastern Arabian Sea (equator $-10^{\circ} \mathrm{N}$ ) moves northward more slowly than does the local convective perturbation (Figs. 7i and 8i) but at a speed close to the northward propagation of the convective perturbation over the Bay of Bengal. This suggests that the wind perturbation over the eastern Arabian Sea is mainly associated with a Gill-type dynamical response to the convective perturbation over the Bay of Bengal. Over the Bay of Bengal, the northward propagation of the OLR perturbation is faster during the bogus onset in May (Fig. 7d) compared to JJA (there is roughly $1 / 4$ of a period between the equator and $15^{\circ} \mathrm{N}$ in May compared to $10^{\circ} \mathrm{N}$ in JJA). This may explain the better agreement between the northward phase propagation of the OLR and wind perturbations over the eastern Arabian Sea (equator- $10^{\circ} \mathrm{N}$ ) in May (Fig. 8f).

The location and the magnitude of the average OLR, SST and wind perturbation patterns described above are due to an ensemble of events, each being the result of a subtle combination of the local MLD, the location of the large-scale convective perturbation, and its associated atmospheric dynamical response. This may lead to quite variable patterns from one intraseasonal convective event to another and thus to nonsignificant average patterns. By computing the distance between each pattern and the average pattern, it is however possible to test how this average perturbation pattern [see Eq. (A13)] is representative of the ensemble of local modes [see Eq. (A3)]. This is illustrated in Fig. 9 showing, for each parameter, the normalized distance between each local mode and the average pattern.

Considering the three parameters, the multivariate patterns in Fig. 7 for JFM are mostly representative of the years 1999, 2001, and 2002 (and 2004 to a lesser degree). For 1998 and 2000, the distance is large for the three parameters (no well-organized event is detected for 2003). The May and JJA average patterns are also quite representative of the ensemble of local modes from the corresponding season. These average patterns are less representative for the years 1999, 2000, and 2001 for May, and for 2003 for JJA. In JJA, there is a similar distance for most local modes, and year 2000 (see section 2) does indeed have ISV patterns close to the average patterns. Note that this distance is smaller for the actual modes of a selected season compared to other seasons showing the specificity of these seasonal average patterns. Also, the local mode patterns of the SST and wind are close to the average pattern when the OLR perturbation pattern is itself close to the average. This shows that the extracted multivariate average patterns are indeed the result of a reproducible coupling (or, at least, covariability) between the three parameters.

\section{b. Maritime Continent}

For this area, there is less seasonal variation of the characteristics of the local modes (Fig. 10). It is interesting to note that while some modes are contemporary with the modes extracted over the Indian Ocean basin (like February 1998, for example), some exist only for one basin (January and March 1999 over the Indian Ocean), and others exist for both basins but with different local characteristics (January 2002 with different time scales). Since there is nothing remarkable in May, only the JFM and JJA seasons are considered.

In JFM, the perturbation for the three parameters (Fig. 11) is maximal south of the equator between $7.5^{\circ}$ and $15^{\circ} \mathrm{S}$, off the northwest coast of Australia for a region with a relatively thin mixed layer (Fig. 4d). Note again the relative minimum of the perturbation over continental Australia compared to adjacent sea for both the OLR and surface wind perturbations. As for the Indian Ocean region, the minimum temperature is reached around $1 / 4$ of a period after the convection maximum (Fig. 12a) and the delay with regard to the wind maximum is shorter, with about $1 / 8$ of a period between the wind maximum and SST minimum (Fig. $12 \mathrm{~b})$. The eastward propagation is hardly visible here in the relative phase field (Fig. 11a), which rather shows a southward propagation (i.e., poleward, as for summer patterns). The surface wind is maximal only shortly af- 

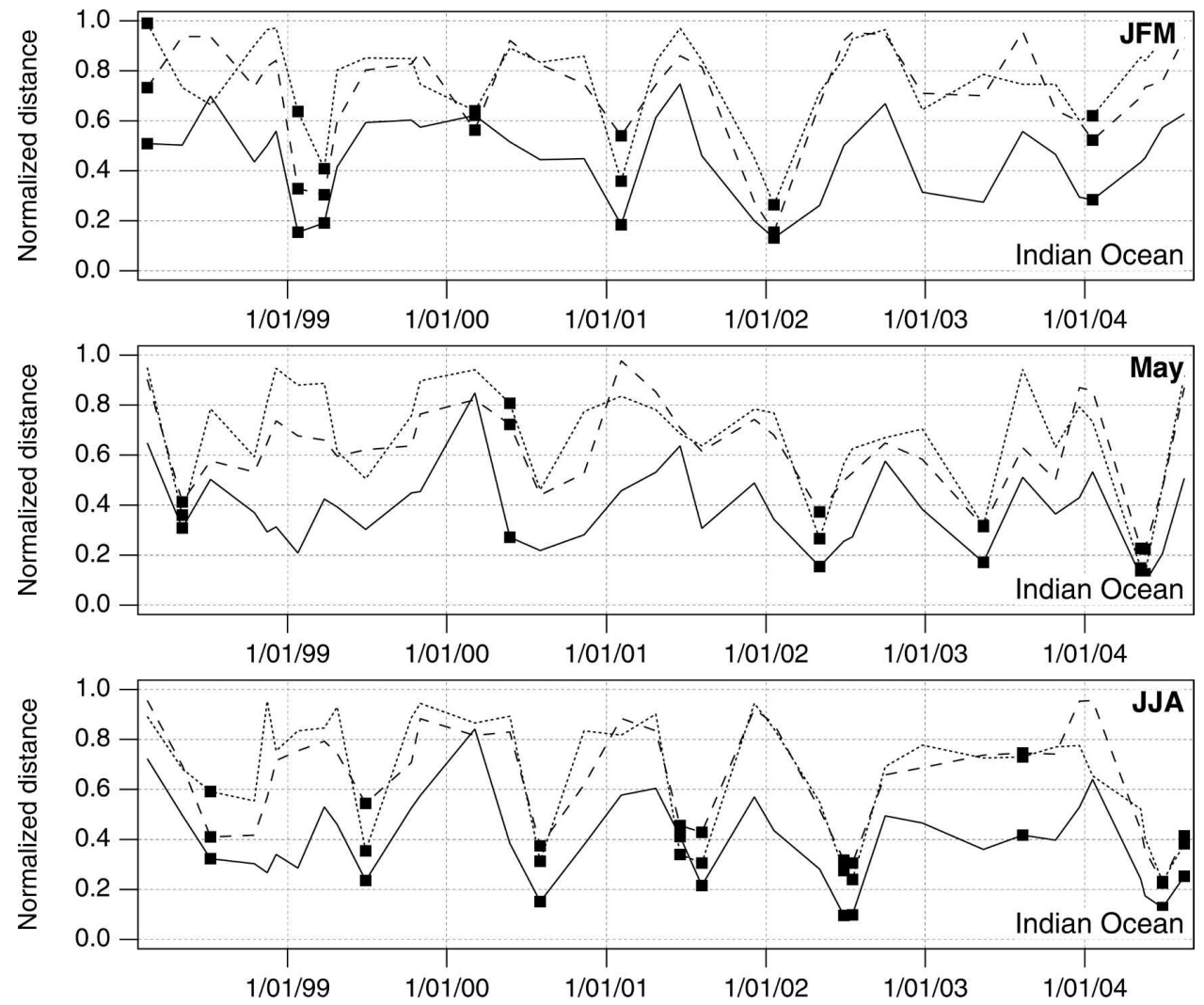

FIG. 9. Normalized distance between the average multivariate patterns in Fig. 7 and the individual local mode patterns for the OLR (solid), the SST (dashed), and the surface wind (dotted) for (top) JFM, (middle) May, and (bottom) JJA. The square markers represent the local modes for the corresponding season. A small distance means that the local mode has a pattern similar to the seasonal average pattern.

ter the maximum convection (Fig. 12c), giving a nearly in-phase modulation of the solar and turbulent surface fluxes that will reinforce the SST perturbation due to surface fluxes.

In JJA, the convective perturbation is maximal between the equator and $15^{\circ} \mathrm{N}$ and propagates northward at a speed $\left(\approx 2^{\circ}\right.$ day $\left.^{-1}\right)$ very close to the phase speed over the Bay of Bengal during the same season (Fig. 11d). The associated SST perturbation is maximal in the South China Sea $\left(10^{\circ} \mathrm{N}, 110^{\circ} \mathrm{E}\right)$ and, more generally, northwest of the maximum OLR perturbation (Fig. 11e), over regions with small MLD (Fig. 4h). The surface wind perturbation is also maximal on the northwest side of the OLR perturbation (Fig. 11f) with maximum amplitude around $10^{\circ} \mathrm{N}$. The wind perturbation is strong and moves northward faster compared to the northern Indian Ocean during the same season (Fig. 11f). As for the Arabian Sea, northeastern regions have a small MLD and the SST perturbation is associated mostly with the surface wind perturbation (the OLR perturbation is small and is probably unrelated to deep convection). South of $10^{\circ} \mathrm{N}$, the SST is minimal $1 / 4$ of a period after the maximum convection (Fig. 12d). North of $10^{\circ} \mathrm{N}$, the SST is rather in quadrature with the surface wind and becomes out of phase with the surface wind farther south (Fig. 12e). In between, around $10^{\circ} \mathrm{N}$, the OLR and wind perturbation are strong and out of phase (Fig. 12f), giving a larger perturbation of the surface fluxes that may explain the larger ISV of the SST (thus, in quadrature with both the OLR and surface wind) here despite the relatively thick mixed layer.

These average patterns are more representative for the end of the 1998-2004 period for both the JFM and the JJA seasons (Fig. 13). Average patterns for both summer and winter are more representative of years 2001, 2002, and 2004.

\section{c. Western Pacific}

Excepted for boreal winter, the standard deviation of the OLR local modes is smaller over this region than over the previous ones (Fig. 14 compared to Figs. 6 and 10). As for the two other basins, the period of the per- 

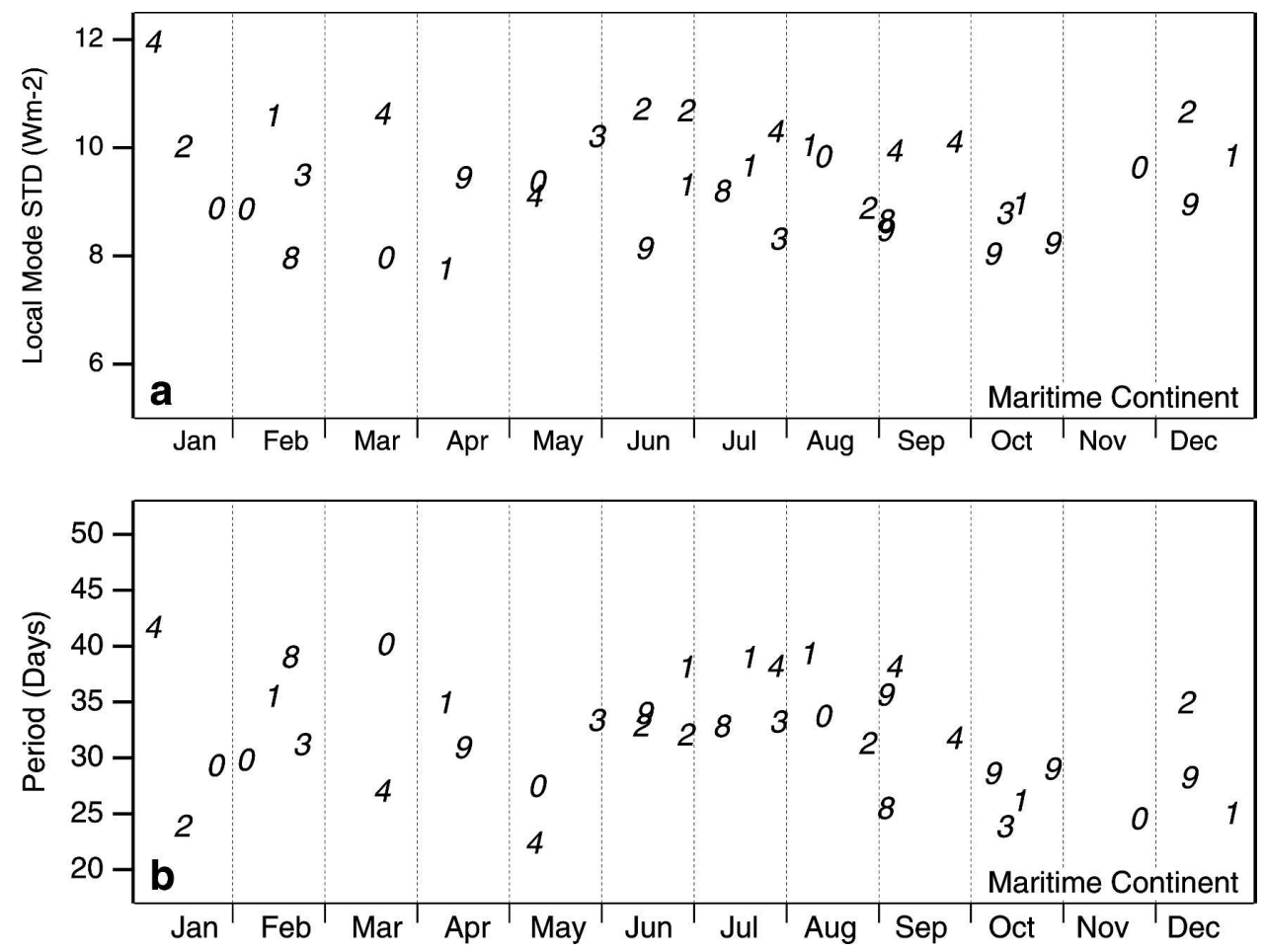

FIG. 10. As in Fig. 6 but for the Maritime Continent area.

turbation is quite dispersed (Fig. 14b). Some local modes are contemporary with the modes extracted over the Indian Ocean basin and the Maritime Continent, like the local modes of 2002 and 2004. Due to the small amplitudes of the other seasons, only the JFM season is considered below.

For the nine events considered, the average OLR pattern over the western Pacific is rather a westward propagation (Fig. 11g). The amplitude of the OLR perturbation is maximal south of the equator near the date line. The corresponding perturbation of the SST is very small (Fig. 11h) and located to the south of the OLR perturbation, in better correspondence with the surface wind perturbation. Minimum SST is reached generally $1 / 4$ of a period after the OLR minimum (Fig. 12g) and between $1 / 4$ and $1 / 8$ of a period after the surface wind maxima (Fig. 12h). These average patterns are mostly representative of years 2002 and 2004 (Fig. 15), which also appear to be modes that are well organized at the Indo-Pacific scale (a mode exists in January for each basin for these years).

\section{Intraseasonal phase relation for selected regions}

On the basis of previous results, the delay between the perturbations of the three parameters for different intraseasonal events is explored in more detail over se- lected regions (Fig. 16). These regions are chosen because of their strong average amplitude and their relatively homogeneous phase for the average patterns of the three parameters. A regional average phase lag between the parameters is computed for each multivariate local mode. This phase lag is expressed in days using the periods shown in Figs. $6 \mathrm{~b}, 10 \mathrm{~b}$, and 14b. The phase lags between the minimum SST, maximum surface wind, and minimum OLR are presented in Fig. 17.

For both the SW and the SE regions, there is a large seasonal cycle of the SST, and intraseasonal events appear clearly to be associated with the development of the convective instability during the warmest season. For the central Indian Ocean (region SC), the seasonal cycle of the SST is smaller and there is intraseasonal OLR variability all along the year. The maximum ISV is nevertheless attained during winter months that are also the warmest season for this region. For these three regions, the surface wind is at a seasonal minimum during winter, except during intraseasonal events when the wind reaches higher values in relation to the westerly wind events.

Over the western Indian Ocean (region SW), the MLD is minimum for JFM and the intraseasonal SST perturbation is relatively large for most events despite the absence of a strong OLR or surface wind perturbation. As shown in Duvel et al. (2004) for the March 

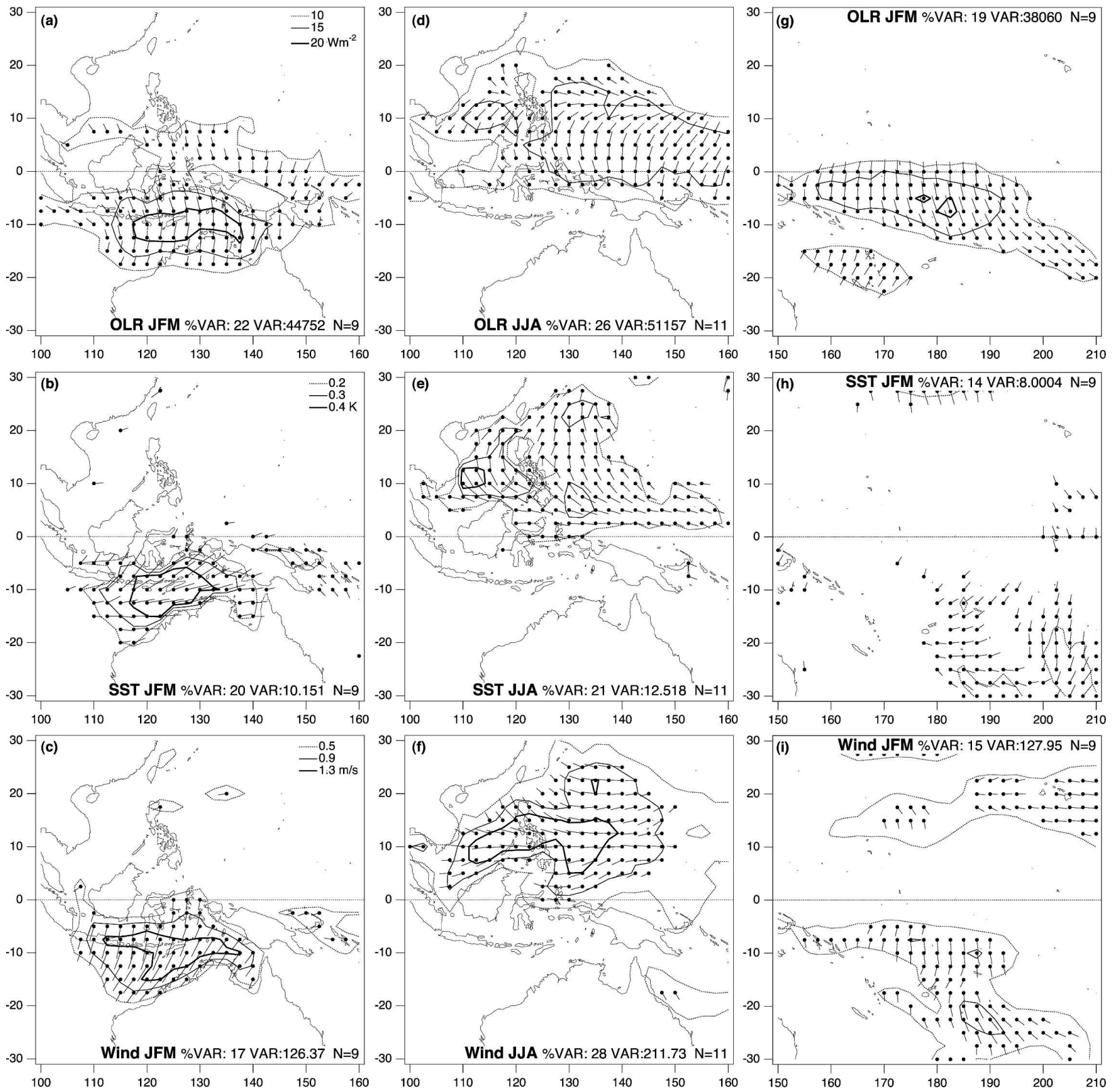

FIG. 11. As in Fig. 7 but for (left) JFM and (middle) JJA over the Maritime Continent and for (right) JFM over the western Pacific Ocean.

1999 event, the ISV of the SST over this region can also result from the warm layer vanishing during the convective event. The SST is minimal $2-8$ days after the maximum of the local OLR perturbation (Fig. 17a). For the two low-frequency (Fig. 6b) events of January 2001 and 2002, the minimum SST is nearly simultaneous with the maximum surface wind, and the delays after the minimum OLR are around, respectively, 3 and 7 days. For the higher-frequency events of January 1999 and 2000 , the wind and convective perturbations are nearly in phase but the delay of the minimum SST is also quite variable and not clearly related to the periods of the events (Fig. 6b). Similar variability in the phase relation between the three parameters is observed for the central Indian Ocean (region SC). Here, the January 1999 event already studied in Harrison and Vecchi (2001) and DRV corresponds to a strong perturbation of the SST that is nearly simultaneous with the maximum wind (Fig. 17b). The same characteristic is observed in January 2002, showing that this strong perturbation is not a unique feature of 1999. For the SE region, strong SST perturbations in 2002 and 2004 are 

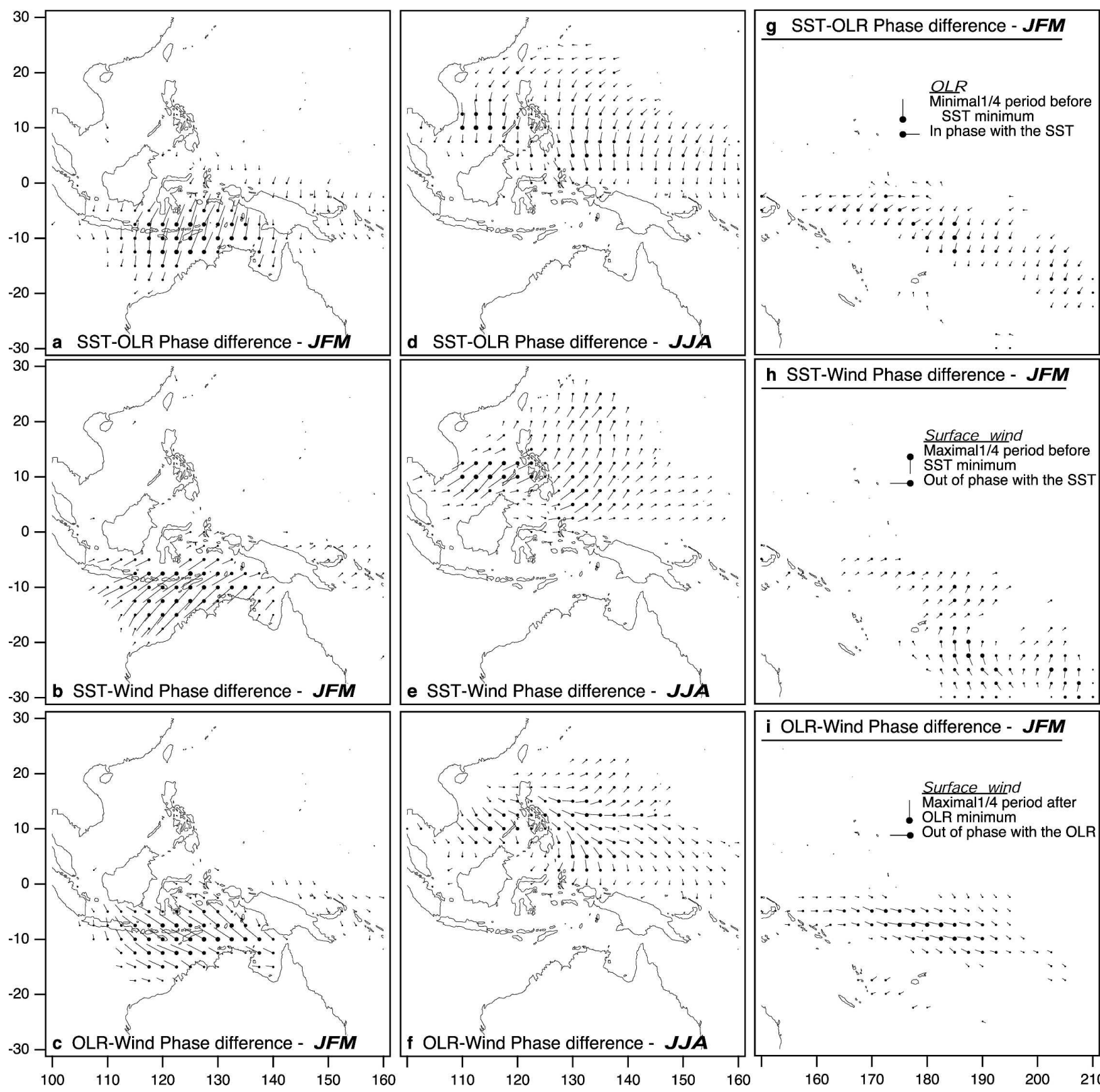

FIG. 12. As in Fig. 8 but for (left) JFM and (middle) JJA over the Maritime Continent and for (right) JFM over the western Pacific Ocean.

associated with large perturbations of both OLR and surface wind.

For the northern Bay of Bengal (region BB), a large seasonal cycle of the SST and intraseasonal convective events appears clearly in association with the development of the convective instability and increased surface wind speed (Fig. 17d). This development is associated with a cooling of the SST during the monsoon season, followed by a secondary warming in September when the convective activity and the surface wind decrease. For the intraseasonal events, the SST is at a minimum
4-10 days after the minimum OLR. The strongest SST perturbations occur in 1998, 2000, 2001, and 2004, for which two strong events are detected, in June and August. For most events, as for the average pattern, the surface wind is maximal only a few days before the minimum SST. For the summer 2000 event (already illustrated in Fig. 3 but for a region of the central Bay of Bengal), the synchronized variations of SST and surface wind for these northern regions are also evident with a lag shorter than 5 days between the minimum OLR and minimum SST. Another example is shown for 

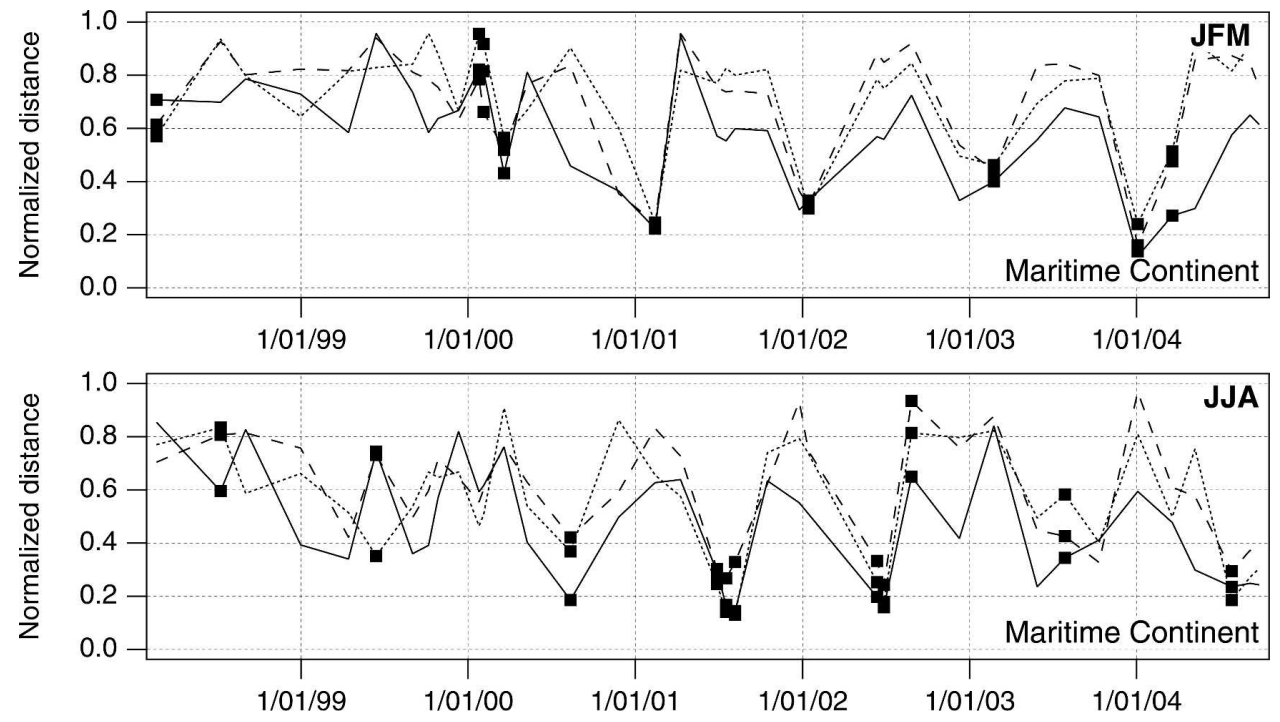

FIG. 13. As in Fig. 9 but for the Maritime Continent area for (top) JFM and (bottom) JJA.

the equatorial region south of the Bay of Bengal (region EQ) for May events corresponding mainly to the bogus monsoons. Here, the seasonal variation of the SST is weak and there is an ISV of the OLR throughout the year. May corresponds to an increase of the surface wind and to a decrease of the SST. SST perturbations are relatively large over this region where the climatological MLD is still relatively small before the bogus monsoon onset (20-30 m in April). In good agreement with the average patterns (Fig. 8), the SST is minimal 5-10 days after the minimum OLR and nearly simultaneous with the surface wind perturbation.
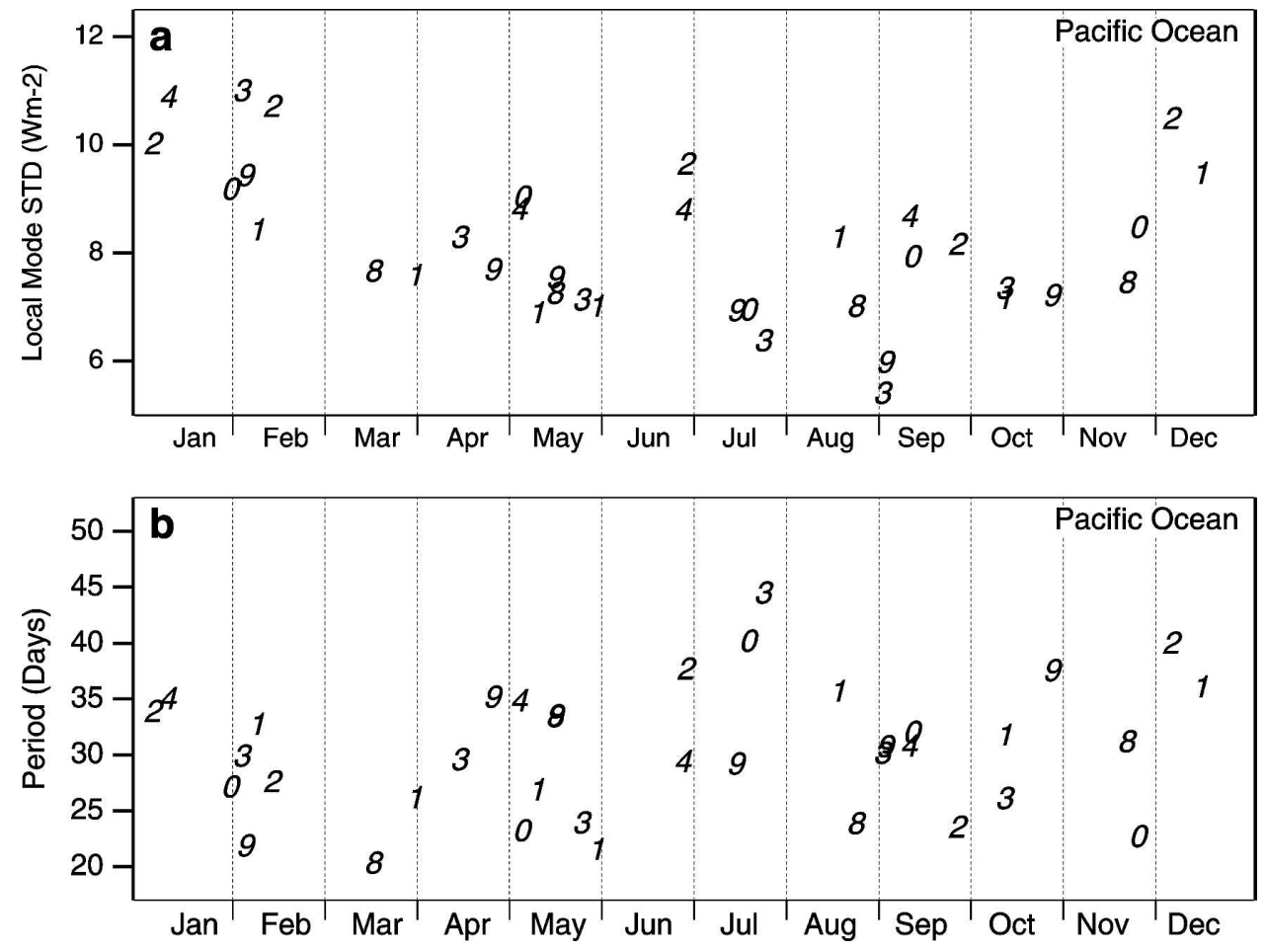

FIG. 14. As in Fig. 6 but for the western Pacific area. 


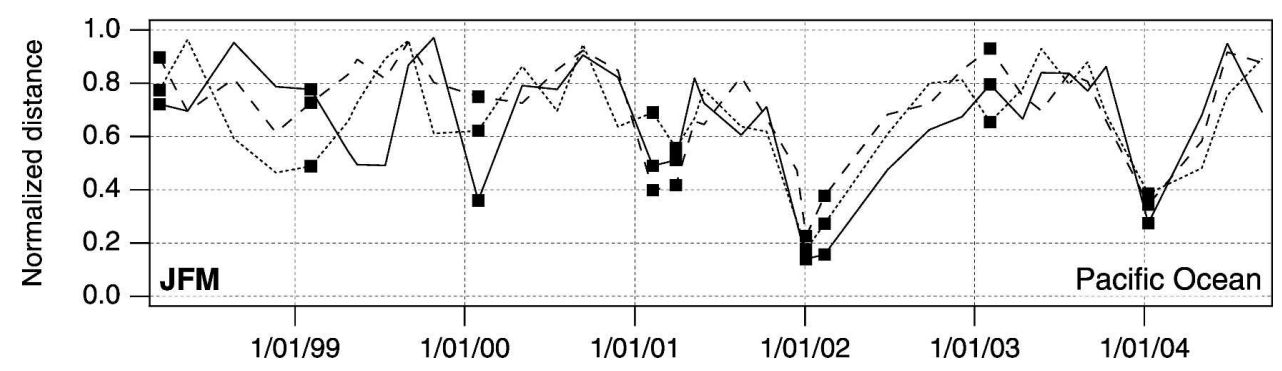

FIG. 15. As in Fig. 9 but for the western Pacific area for JFM.

\section{Summary and discussion}

It is important to understand the source of the largescale organized coupling between the convection and the SST at an intraseasonal time scale in order to create a correct representation of these processes in global models and thus for the predictability of intraseasonal events. Using available observational datasets of SST, OLR, and surface wind for $7 \mathrm{yr}$, this study is an attempt to retrieve the main characteristics of the ISV of the SST field and to trace the source of this variability. The use of the relatively new TMI SST dataset makes it possible to analyze the ISV of the SST with more accuracy than did previous studies using the Reynolds and Smith (1994) dataset.

This study first considers the relationship between a climatological MLD and the amplitude of the ISV of the SST. For the Indo-Pacific region, there is larger SST ISV where the mixed layer is thinner, as expected for a slab ocean integrating passively atmospheric forcing. Applied in the intraseasonal range, the simple model of Hasselmann (1976) gives an ISV of the SST that is proportional to the ISV of the surface flux and inversely proportional to the MLD and frequency. Using climatological MLD estimates, TMI SST, and NCEP surface fluxes, it is shown that this idealized model holds statistically within the 20-90-days range for most region of the summer hemisphere. This suggests that a large frac-

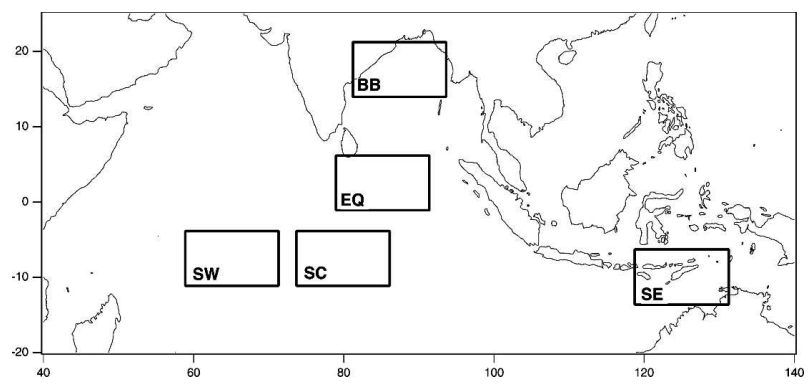

FIG. 16. Selected regions for studying the response of wind and SST to large-scale organized OLR perturbations for each intraseasonal event. tion of the ISV of the SST in the tropical Indo-Pacific results from a climatological mixed layer that integrates surface forcing (heat flux or wind-driven subsurface cooling). In such a case, one may expect a larger ISV of the SST not only for regions with larger ISV of the surface fluxes or thinner mixed layers but also for an ISV at lower frequencies (the ISV of the SST will be twice as large for a 40-day oscillation of the forcing as for a 20-day oscillation of the same amplitude).

One may question this result since several processes in (1), and in particular the intraseasonal variability of the mixed layer, are neglected in (4). However, analysis of model mixed layer variability (not shown) in the forced OGCM simulations used in DRV shows that intraseasonal variability of the mixed layer depth is small in the Tropics when compared to the seasonal or interannual variability. The only exception is in the equatorial zone. This can be understood since the zonal wind directly accelerates the zonal flow in the equatorial band, giving fast upper-current changes and deepening of the mixed layer by shear. The slower dynamics at higher latitudes make the currents less responsive and thus vertical shear more difficult to generate at an intraseasonal time scale. This point was illustrated for only two intraseasonal events in DRV but the underlying physics is probably also valid for other regions and events. Similarly, the deepening of the mixed layer due to buoyancy forcing is more efficient at longer time scales than on an intraseasonal time scale. Intraseasonal variability of the mixed layer is thus smaller than the seasonal or interannual variability.

In addition, the diagnostic made in section 3 does not make it possible to distinguish between the role of surface heat fluxes and wind-driven subsurface cooling in the intraseasonal variability. Both are likely to contribute, but several arguments tend to show that the surface net heat flux is the dominant effect in most regions. First, several previous studies have already suggested that surface heat fluxes are dominant for MJO-driven variability (e.g., Shinoda and Hendon 1998, 2001; DRV). Second, the good statistical and quantitative 




다은

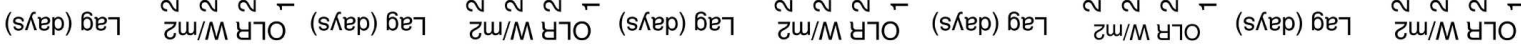

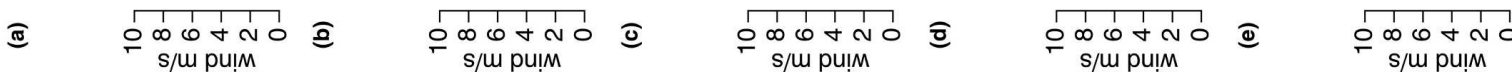


consistency obtained with (4) suggests that the regional SST ISV matches well with the amplitude of the flux variability, even with a climatological MLD. Third, as suggested above, the mixed layer intraseasonal variability in most regions of the Tropics is quite weak compared, for example, to the seasonal variability. This suggests that there is probably relatively weak flux variability at the bottom of the mixed layer at these time scales. However, a precise quantification of the relative role of the surface heat flux and wind-driven subsurface cooling in the SST ISV deserves detailed studies of the upper-ocean heat budget at intraseasonal time scales.

The link between the large-scale organized ISV of tropical convection and the ISV of the SST is examined using an adaptation of the LMA analysis (Goulet and Duvel 2000). This new multivariate approach is applied to determine the average patterns of the SST and the surface wind perturbation as related to large-scale convective events. Results show that, for the studied period of 1998-2004, seasonal average multivariate patterns at the basin scale are robust and represent around half of the intraseasonal events for a given season and a given basin (Indian Ocean, Maritime Continent, and western Pacific). These patterns are relatively close to the average CEOF patterns computed on time sections of the corresponding season. Mathematically, the only difference is that an average CEOF will be computed on fixed time sections defined from calendar days. The average LMA is also an average CEOF but it is computed from the time sections previously extracted from the LMA, which are centered on large-scale organized events (and on the corresponding season). Compared to an average CEOF analysis, the LMA approach makes it possible to (i) extract time sections centered on large-scale organized perturbations, (ii) give specific pattern and spectral characteristics for each extracted time section, and (iii) test how the average pattern represents perturbations that follow one another in time. The LMA applied to each basin independently extracts organized events at the basin scale that are contemporary for the three basins (such as for January 2002 and 2004). This interbasin organization is consistent with a canonical MJO perturbing the whole Indo-Pacific area. However, other events are organized only on a basin scale suggesting that the interbasin organization is not a necessary condition for the existence of strong organized coupled perturbations.

During summer in the Indian Ocean, the OLRrelated SST ISV is maximal over a region extending from the equator up to the northern limits of the Arabian Sea and the Bay of Bengal. The ISV patterns of the three parameters present reproducible specificities for intraseasonal events related to "bogus monsoon onsets" in May, and actual intraseasonal variations during the monsoon. During the monsoon, SST and surface wind perturbations in the Bay of Bengal show more of the characteristics of a standing oscillation between the equator and the northern Bay of Bengal, with minimum amplitude around $10^{\circ} \mathrm{N}$. The general picture for the Arabian Sea and continental India is a wind perturbation mainly related to the development of the convection over the Bay of Bengal, which is in agreement with results shown in Joseph and Sijikumar (2004). Over the western Arabian Sea, the SST perturbation is mostly due to this wind perturbation and could be related in part to the associated variations of the upwelling. Compared to the JJA season, there is a faster northward propagation across the Bay of Bengal in May, which is associated with an eastward propagation of the intraseasonal perturbation. The resulting wind perturbation lags (a quadrature) the OLR, which is in agreement with a Gill-type dynamical response to an eastward-moving convective perturbation. The picture is different for the northwestern Pacific in JJA. If the northward propagation of the convective perturbation is similar, the associated SST and wind perturbations do not exhibit opposite phases as is seen during JJA over the Bay of Bengal. Eastward movement of the perturbations is also barely detectable and the surface wind perturbation propagates northward faster than the convective perturbation. The SST perturbation is maximal over the northwestern region where the MLD is small and around $10^{\circ} \mathrm{N}$ where OLR and surface wind perturbations are out of phase (i.e., solar and turbulent fluxes are in phase).

During boreal winter, the ISV of the OLR extends throughout most of the Indian Ocean and western Pacific. Nevertheless, the OLR-related SST and surface wind responses are large only between $5^{\circ}$ and $10^{\circ} \mathrm{S}$ over the central Indian Ocean and off the northwest coast of

FIG. 17. Relative delay between minimum OLR (square) and minimum SST (circle) and between minimum OLR and the maximum surface wind (triangle) for the five regions defined in Fig. 16: regions (a) SW, (b) SC, and (c) SE for JFM; (d) region BB for JJA; and (e) region EQ for May. The size of the markers is proportional to the local amplitude of the event for each parameter. For each region, the smoothed time series for the average OLR (solid, second left axis), SST (filled in gray, right axis), and surface wind (dotted, first left axis) are also shown. 
Australia. The eastward propagation of the convective perturbation is clear only for the Indian Ocean basin. For most regions, the various ISV events are characterized by a minimum SST occurring $1 / 4$ of a period after the maximum convection. However, especially for some strong events over the central Indian Ocean during winter, but also for the central Bay of Bengal region during summer, the SST is a minimum during or just after the surface wind maximum.

The fact that, even for a given region and a given season, OLR and surface wind have different intraseasonal phase relations for different events is not surprising. This is because the response of the surface wind depends more on the timing and location of the largescale convective perturbation than on the local convective perturbation. However, the variable delay between the maximum perturbation of the driving surface flux parameters (convective cloudiness and surface wind) and the SST is more intriguing and deserves further discussion.

If the OLR (proxy for the surface solar flux perturbations) and the surface wind (proxy for the surface turbulent heat flux) are out of phase (i.e., solar and turbulent flux are in phase), as for example, over the northwest Pacific during JJA around $10^{\circ} \mathrm{N}$ (Fig. 12f), and if those surface fluxes are the main source for SST perturbations, the time of these maximum perturbation should correspond to the time of the maximum derivative of the SST shown in (1). In such a case, the lag between the maximum surface fluxes and the minimum SST is of the order of $1 / 4$ of a period, as is the case in the northwest Pacific Ocean around $10^{\circ} \mathrm{N}$ in JJA (Fig. $12 \mathrm{e})$. However, as shown in the previous sections, surface wind and OLR ISV perturbations have various strengths and relative phase relationships depending on the region and season. In particular, for eastwardmoving Gill-type atmospheric perturbations, the surface wind maximum will lag the convective maximum, reducing the whole impact of the surface flux perturbation on the SST and giving a larger variety of SSTOLR and SST-wind phase relationships. Since the wind is generally maximal between 0 and $1 / 4$ of a period after the convective maximum (Figs. 8 and 12), an SST driven by surface fluxes should be theoretically minimal between $1 / 4$ and $1 / 2$ a period after the convection maximum. An SST minimum during or just after the surface wind maximum thus means either that the surface wind does not impact the SST significantly or, on the contrary, that the surface wind strongly and rapidly cools the surface, as is the case, for example, during warm layer destruction. In addition, and this could be an important feature, the ISV is not a purely sinusoidal signal and the wind reinforcement may be more abrupt than expected from the filtered signal. This will give an SST response (either due to surface fluxes, subsurface cooling, or upwelling) with a shorter delay compared to the time scale between the two perturbations detected from the OLR. A good example is shown in Fig. 3d where an abrupt wind burst after calm conditions in the beginning of July 2000 can be seen, which may explain the short delay between the maximum wind and minimum SST.

To conclude, despite the relatively short time series used here $(7 \mathrm{yr})$, this study shows relatively robust patterns for the response of both the surface wind and the SST to large-scale organized convection. This shows in particular a strong SST ISV south of the equator in the Indian Ocean and north of Australia during winter that is associated with a relatively thin mixed layer. This is in contrast with the weak SST response to the ISV of the convection found over the western Pacific for the $7 \mathrm{yr}$ considered. The exact nature of the processes of SST cooling still has to be explored in more detail, especially in order to understand the origin of the frequently short delay between the maximum wind and the minimum SST. To this end, detailed modeling analyses of the ocean mixed layer variabilities with associated in situ measurements are necessary to examine the role of different processes such as warm-layer formations and subsurface cooling. Due to the large and reproducible intraseasonal SST perturbations found here, correctly representing this coupling in general circulation models appears to be more and more necessary.

Acknowledgments. TMI data are produced by $\mathrm{Re}-$ mote Sensing Systems and sponsored, in part, by NASA's Earth Science Information Partnerships (ESIP), a federation of information sites for earth science, and by the NOAA-NASA Pathfinder Program for early EOS products: principal investigator, Frank Wentz. The comments of two anonymous referees were very useful for improving this paper.

\section{APPENDIX}

\section{Computation of the Local Modes for One Parameter}

The LMA technique is based on a CEOF computation on a running time section (of 120 days here). For each time step $(\mathrm{m})$ of the running analysis, only the leading $C E O F$ is retained, corresponding to one particular pattern $\tilde{Z}_{p}^{m}(x)$ explaining a percentage of the variance, $\Pi_{p}^{m}$. The maxima in the $\Pi_{p}^{m}$ time series are then identified and the leading CEOFs of the time section corresponding to these maxima are called local 
modes. One can demonstrate that the spatial patterns, $\tilde{Z}_{p}^{m}(x)$, of these local modes are more persistent in time and/or more spatially coherent than the patterns of other leading CEOFs (Goulet and Duvel 2000).

Mathematically, for each time step $(m)$, we consider the 120-day time series $S_{p}^{m}(x, t)$ of parameter $(p)$, for each region $(x)$ with $1 \leq x \leq N$ and $1 \leq t \leq T(T=120)$. The leading eigenvector is computed from the crossspectrum matrix $\tilde{\zeta}_{p}^{m}$ defined as

$$
\tilde{\zeta}_{p}^{m}\left(k, k^{\prime}\right)=\sum_{x=1}^{N} \tilde{F}_{p}^{m}(x, k) \tilde{F}_{p}^{m *}\left(x, k^{\prime}\right),
$$

where $\tilde{X}$ are complex numbers and $\tilde{X}^{*}$ their complex conjugate, $\mathrm{k}$ is the harmonic number (for the whole spectrum $1 \leq k \leq T / 2)$, and $\tilde{F}_{p}^{m}(x, k)$ represents the Fourier coefficients defined as

$$
\tilde{F}_{p}^{m}(x, k)=\frac{\sqrt{2}}{T} \sum_{t=1}^{T} w(t) S_{p}^{m}(x, t) e^{-2 i \pi k t / T},
$$

where $w(t)$ is the Welch window. Since the complex EOF has to be applied to a restricted time-spectral domain, $S_{p}(x, t)$ is filtered prior to the analysis and $\tilde{\zeta}_{p}^{m}$ can be computed on a restricted time-spectral band $\left[k_{1}, k_{2}\right]$ so that the dimension of the matrix is only $K_{n} \times K_{n}$ with $K_{n}=k_{2}-k_{1}+1$. The leading eigenvectors of $\tilde{\zeta}_{p}^{m}$ are a complex normalized spectrum $\tilde{\psi}_{p}^{m}(k)$ from which we can retrieve the spatial eigenvectors $\tilde{Z}_{p}^{m}(x)$ by

$$
\tilde{Z}_{p}^{m}(x)=\sum_{k=k_{1}}^{k_{2}} \tilde{F}_{p}^{m}(x, k) \tilde{\psi}_{p}^{m *(k) .}
$$

For a region $x$, the reconstructed time series associated with the local mode of the time step $(m)$ is given by

$$
S_{p}^{m}(x, t)=A_{p}^{m}(x) B^{m}(t) \cos \left[\phi_{p}^{m}(x)+\chi^{m}(t)\right],
$$

where $A_{p}^{m}(x)=\left|\tilde{Z}_{p}^{m}(x)\right|$ and $\phi_{p}^{m}(x)=\operatorname{Arg}\left[\tilde{Z}_{p}^{m}(x)\right]$ are, respectively, the regional standard deviation and phase of the leading complex eigenvector $\tilde{Z}_{p}^{m}(x)$. Here, $B^{m}(t)$ and $\chi^{m}(t)$ represent, respectively, the amplitude and phase obtained by the inverse Fourier transform of $\tilde{\psi}_{p}^{m}(k)$. The summation of $A_{p}^{m}(x)^{2}$ over all regions is the variance of the leading CEOF. It is possible to define a regional representation index $\left[R_{p}^{m}(x)\right]$ for the local mode $\mathrm{m}$ as

$$
R_{p}^{m}(x)=\frac{A_{p}^{m}(x)^{2}}{V_{p}^{m}(x)}
$$

where

$$
V_{p}^{m}(x)=\sum_{k=k_{1}}^{k_{2}} \tilde{F}_{p}^{m}(x, k) \tilde{F}_{p}^{m *}(x, k)
$$

is the variance (weighted by the Welch window) of the parameter $(p)$ in the selected frequency band $\left[k_{1}, k_{2}\right]$. The term $R_{p}^{m}(x)$ represents for each region and the corresponding local mode the part of the regional intraseasonal perturbation that is coherent at large scales. Note that the percentage of variance is also given by

$$
\Pi_{p}^{m}=\frac{\sum_{x=1}^{N} A_{p}^{m 2}(x)}{\sum_{x=1}^{N} V_{p}^{m}(x)} .
$$

\section{a. Multivariate analysis}

This technique may be further used to study perturbations of a second parameter $(q)$ associated with the perturbation of the leading parameter $(p)$. Indeed, the projection [Eq. (A3)] of the normalized spectrum $\tilde{\psi}_{p}^{m}(k)$ may be done with the Fourier coefficient $\tilde{F}_{q}^{m}(x, k)$ of another parameter $(q)$. In such a case, the obtained $\tilde{Z}_{p, q}^{m}(x)$ represents the spatial pattern of the perturbation of $(q)$ related to the large-scale organized perturbation of $(p)$, through a "spectral key" $\tilde{\psi}_{p}^{m}(k)$. In other words, the distribution of amplitudes and phases of $\tilde{Z}_{p, q}^{m}(x)$ represents the part of the regional signal of $(q)$ that is correlated with the large-scale organized perturbation of $(p)$ represented by the local mode $(m)$. As for the reference parameter $(p)$, a regional representation index $R_{p, q}^{m}(x)$ may be defined as

$$
R_{p, q}^{m}(x)=\frac{A_{p, q}^{m}(x)}{V_{q}^{m}(x)} .
$$

\section{b. Average multivariate patterns}

The average pattern is computed for the reference parameter from a cross-spectrum matrix of dimensions $(N, N)$, where $N$ is the number of regions, as described in Goulet and Duvel (2000). Each element of the matrix is an average cross spectrum computed from a given selection (an ensemble $S$ ) of local modes. For the present study, $p$ is the OLR and the ensemble $S$ is a particular season. This selection may be based on season or on another criterion. Each element of this mean cross-spectrum matrix $\tilde{\breve{\zeta}}_{p, s}$ is defined as

$$
\overline{\tilde{\zeta}}_{p, s}\left(x, x^{\prime}\right)=\sum_{m \in S} \sum_{k=k_{1}}^{k_{2}} \tilde{L}_{p}^{m}(x, k) \tilde{L}_{p}^{m *}\left(x^{\prime}, k\right),
$$

where $\tilde{L}_{p}^{m}(x, k)$ is the spectrum for the parameter $p$ and region $x$, corresponding to the local mode $\mathrm{m}$ :

$$
\tilde{L}_{p}^{m}(x, k)=\tilde{Z}_{p}^{m}(x) \tilde{\psi}_{p}^{m}(k) .
$$

Note that the pattern obtained is generally very close (but the percentage of variance is smaller) if one uses 
the original spectra $\tilde{F}_{p}^{m}(x, k)$ instead of the local mode spectra $\tilde{L}_{p}^{m}(x, k)$. Using the normalized first eigenvector $\tilde{Z}_{p, s}(x)$ of the average cross-spectrum matrix $\tilde{\zeta}_{p, s}$, and the regional spectra $\tilde{L}_{p}^{m}(x, k)$ [or $\left.\tilde{F}_{p}^{m}(x, k)\right]$, the average spectrum $\tilde{\psi}_{f, s}^{m}(k)$ for each local mode window $(m)$ is given by

$$
\tilde{\psi}_{p, s}^{m}(k)=\sum_{x} \tilde{L}_{p}^{m}(x, k) \tilde{Z}_{p, s}^{*}(x) .
$$

These spectra are then normalized such that

$$
\sum_{m \in S} \sum_{k=k_{1}}^{k_{2}}\left|\tilde{\psi}_{p, s}^{m}(k)\right|^{2}=1 .
$$

Then, for each parameter $q$, an average pattern corresponding to these spectra (which are spectral keys corresponding to the average pattern of the reference parameter) can be computed from the spectra $\tilde{L}_{q}^{m}(x, k)$ [or $\left.\tilde{F}_{q}^{m}(x, k)\right]$ :

$$
\tilde{Z}_{q, s}^{p}(x)=\sum_{m \in S} \sum_{k=k_{1}}^{k_{2}} \tilde{L}_{q}^{m}(x, k) \tilde{\psi}_{p, s}^{m} *(k) .
$$

These are the average patterns of the perturbation of the parameter $q$ associated with the large-scale organized perturbations of the reference parameter $p$ [one may verify that $\left.\tilde{Z}_{p, s}^{p}(x)=\tilde{Z}_{p, s}(x)\right]$. These patterns are used in section 4 to analyze the average relation between the OLR, the SST, and the surface wind intraseasonal perturbations. Since the normalized spectra, $\tilde{\psi}_{p, s}^{m}(k)$, are not from parameter $q$, the principal component time series corresponding to $\tilde{Z}_{q, s}^{p}(x)$ and the corresponding variance (and percentage of variance) have to be computed by a projection of the $\tilde{L}_{q}^{m}(x, k)$ [or $\left.\tilde{F}_{q}^{m}(x, k)\right]$ on $\tilde{Z}_{q, s}^{p}(x)$.

The LMA makes it possible to measure the resemblance between an average pattern and the patterns for each local mode. This is very important in verifying if this average pattern is only a mathematical object or if it is representative of the different events, that is, if it is appropriate for giving a physical interpretation of the average pattern. As in Goulet and Duvel (2000), this resemblance is computed as a normalized distance between the complex eigenvectors representing the average pattern $\tilde{Z}_{q, s}^{p}(x)$ and the pattern of each local mode, $\tilde{Z}_{q}^{m}(x)$. A normalized distance of 0 means that the patterns are identical and normalized distance of 1 means that the two patterns are orthogonal.

\section{REFERENCES}

Anderson, S. P., R. A. Weller, and R. Lukas, 1996: Surface buoyancy forcing and the mixed layer of the western Pacific warm pool: Observations and 1D model results. J. Climate, 9, 30563085 .
Bhat, G. S., G. A. Vecchi, and S. Gadgil, 2004: Sea surface temperature of the Bay of Bengal derived from the TRMM Microwave Imager. J. Atmos. Oceanic Technol., 21, 1283-1290.

Chelton, D. B., F. J. Wentz, C. L. Gentemann, R. A. de Skoeze, and M. G. Schlax, 2000: Satellite microwave SST observations of transequatorial tropical instability waves. Geophys. Res. Lett., 27, 1239-1242.

de Boyer Montégut, C., G. Madec, A. S. Fischer, A. Lazar, and D. Iudicone, 2004: Mixed layer depth over the global ocean: An examination of profile data and a profile-based climatology. J. Geophys. Res., 109, C12003, doi:10.1029/2004JC002378.

Duvel, J. P., R. Roca, and J. Vialard, 2004: Ocean mixed layer temperature variations induced by intraseasonal convective perturbations over the Indian Ocean. J. Atmos. Sci., 61, 10041023.

Flatau, M. K., P. J. Flatau, and D. Rudnick, 2001: The dynamics of double monsoon onsets. J. Climate, 14, 4130-4146.

Gill, A. E., 1980: Some simple solutions for heat-induced tropical circulation. Quart. J. Roy. Meteor. Soc., 106, 447-462.

Goswami, B. N., and R. S. Ajaya Mohan, 2001: Intraseasonal oscillations and interannual variability of the Indian summer monsoon. J. Climate, 14, 1180-1198.

Goulet, L., and J.-P. Duvel, 2000: A new approach to detect and characterize intermittent atmospheric oscillations: Application to the intraseasonal oscillation. J. Atmos. Sci., 57, $2397-$ 2416.

Harrison, D. E., and A. Vecchi, 2001: January 1999 Indian Ocean cooling event. Geophys. Res. Lett., 28, 3717-3720.

Hasselmann, K., 1976: Stochastic climate models. 1: Theory. Tellus, 28, 473-485.

Inness, P. M., and J. M. Slingo, 2003: Simulation of the MaddenJulian oscillation in a coupled general circulation model. Part I: Comparison with observations and an atmosphere-only GCM. J. Climate, 16, 345-364.

Jones, C., D. E. Waliser, and C. Gautier, 1998: The influence of the Madden-Julian oscillation on ocean surface heat fluxes and sea surface temperature. J. Climate, 11, 1057-1072.

Joseph, P. V., and S. Sijikumar, 2004: Intraseasonal variability of the low-level jet stream of the Asian summer monsoon. $J$. Climate, 17, 1449-1458.

Kanamitsu, M., W. Ebisuzaki, J. Woollen, S.-K. Yang, J. J. Hnilo, M. Fiorino, and G. L. Potter, 2002: NCEP-DOE AMIP-II reanalysis (R-2). Bull. Amer. Meteor. Soc., 83, 1631-1643.

Kawamura, R., 1988: Intraseasonal variability of sea surface temperature over the tropical western Pacific. J. Meteor. Soc. Japan, 66, 1007-1012.

Kindle, J. C., and J. D. Thompson, 1989: 26 and 50-day period oscillations in the Indian Ocean: Model results. J. Geophys. Res., 94, 4721-4736.

Lawrence, D. M., and P. J. Webster, 2002: The boreal summer intraseasonal oscillation: Relationship between northward and eastward movement of convection. J. Atmos. Sci., 59, $1593-1606$

Lengaigne, M., J.-P. Boulanger, C. Menkes, S. Masson, G. Madec, and P. Delecluse, 2002: Ocean response to the March 1997 westerly wind event. J. Geophys. Res., 107, 8015, doi:10.1029/ 2001JC000841.

Liebmann, B., and C. A. Smith, 1996: Description of a complete (interpolated) outgoing longwave radiation dataset. Bull. Amer. Meteor. Soc., 77, 1275-1277.

Madden, R. A., and P. R. Julian, 1994: Observations of the 40-50day tropical oscillation-A review. Mon. Wea. Rev., 122, 814837. 
Maloney, E. D., and A. H. Sobel, 2004: Surface fluxes and ocean coupling in the tropical intraseasonal oscillation. J. Climate, 17, 4368-4386.

McPhaden, M. J., 1999: Genesis and evolution of the 1997-1998 El Niño. Science, 283, 950-954.

Reynolds, R. W., and T. M. Smith, 1994: Improved global sea surface temperature analyses using optimum interpolation. $J$. Climate, 7, 929-948.

Sengupta, D., and M. Ravichandran, 2001: Oscillations of Bay of Bengal sea surface temperature during the 1998 summer monsoon. Geophys. Res. Lett., 28, 2033-2036.

—, B. N. Goswami, and R. Senan, 2001: Coherent intraseasonal oscillations of ocean and atmosphere during the Asian summer monsoon. Geophys. Res. Lett., 28, 4127-4130.

Shinoda, T., and H. H. Hendon, 1998: Mixed layer modeling of intraseasonal variability in the tropical western Pacific and Indian Oceans. J. Climate, 11, 2668-2685.

— Madden-Julian oscillation in the western equatorial Pacific. J. Climate, 14, 4147-4165.

— _ _ - and J. Glick, 1998: Intraseasonal variability of surface fluxes and sea surface temperature in the tropical western Pacific and Indian Oceans. J. Climate, 11, 1685-1702.

Tsai, P. T. H., J. J. O'Brien, and M. E. Luther, 1992: The 26-day oscillation observed in the satellite sea surface temperature measurements in the equatorial western Indian Ocean. $J$. Geophys. Res., 97, 9605-9618.

Vecchi, G. A., and D. E. Harrison, 2002: Monsoon breaks and subseasonal sea surface temperature variability in the Bay of Bengal. J. Climate, 15, 1485-1493.

Waliser, D. E., K. M. Lau, and J.-H. Kim, 1999: The influence of coupled sea surface temperatures on the Madden-Julian oscillation: A model perturbation experiment. J. Atmos. Sci., 56, 333-358.

Webster, P. J., V. O. Magana, T. N. Palmer, J. Shukla, R. A. Tomas, M. Yanai, and T. Yasunari, 1998: Monsoons: Processes, predictability, and the prospects for prediction. J. Geophys. Res., 103 (C7), 14 451-14 510.

Weller, R. A., and S. P. Anderson, 1996: Surface meteorology and air-sea fluxes in the western equatorial Pacific warm pool during the TOGA Coupled Ocean-Atmosphere Response Experiment. J. Climate, 9, 1959-1992.

Wentz, F. J., C. Gentemann, D. Smith, and D. Chelton, 2000: Satellite measurements of sea-surface temperature through clouds. Science, 288, 847-850.

Woolnough, S. J., J. M. Slingo, and B. J. Hoskins, 2000: The relationship between convection and sea surface temperature on intraseasonal timescales. J. Climate, 13, 2086-2104.

Zhang, C., and M. Dong, 2004: Seasonality in the Madden-Julian oscillation. J. Climate, 17, 3169-3180. 